\title{
Combination anti-HIV-1 antibody therapy is associated with increased virus-specific T cell immunity
}

\author{
Julia Niessl 1,2,3, Amy E. Baxter1,2,3,9, Pilar Mendoza4, Mila Jankovic ${ }^{4}$, Yehuda Z. Cohen ${ }^{4}$, \\ Allison L. Butler ${ }^{4}$, Ching-Lan Lu, ${ }^{4,10}$, Mathieu Dubé1, Irina Shimeliovich4, Henning Gruell5,6,7, \\ Florian Klein $\mathbb{1}^{5,7,8}$, Marina Caskey ${ }^{4}$, Michel C. Nussenzweig ${ }^{4,11 \star}$ and Daniel E. Kaufmann ${ }^{1}{ }^{1,2,3,11 \star}$
}

\begin{abstract}
Combination antiretroviral therapy (ART) is highly effective in controlling human immunodeficiency virus (HIV)-1 but requires lifelong medication due to the existence of a latent viral reservoir ${ }^{1,2}$. Potent broadly neutralizing antibodies (bNAbs) represent a potential alternative or adjuvant to ART. In addition to suppressing viremia, bNAbs may have $T$ cell immunomodulatory effects as seen for other forms of immunotherapy ${ }^{3}$. However, this has not been established in individuals who are infected with HIV-1. Here, we document increased HIV-1 Gag-specific $\mathrm{CD}^{+} \mathrm{T}$ cell responses in the peripheral blood of all nine study participants who were infected with HIV-1 with suppressed blood viremia, while receiving bNAb therapy during ART interruption ${ }^{4}$. Increased $\mathrm{CD4}^{+} \mathrm{T}$ cell responses were detected in eight individuals. The increased $T$ cell responses were due both to newly detectable reactivity to HIV-1 Gag epitopes and the expansion of pre-existing measurable responses. These data demonstrate that bNAb therapy during ART interruption is associated with enhanced HIV-1-specific T cell responses. Whether these augmented $\mathrm{T}$ cell responses can contribute to bNAb-mediated viral control remains to be determined.
\end{abstract}

HIV-1 infection is characterized by high initial levels of plasma viremia that are variably controlled by virus-specific $\mathrm{CD}^{+} \mathrm{T}$ cell responses $^{5,6}$. Individuals who fail to control viremia, rapidly develop immunodeficiency. In contrast, strong, broad HIV-specific CD8 ${ }^{+}$ and $\mathrm{CD} 4^{+} \mathrm{T}$ cell responses have been associated with spontaneous viral control (that is, elite controllers, viral load $<50$ copies per $\mathrm{ml}$ ) and delayed progression to AIDS $^{7-9}$.

ART is highly effective in maintaining viral suppression but does not boost host antiviral immunity because it limits antigen availability. In contrast, antibodies do not prevent virus replication or production and, unlike small molecule drugs, they have dual functionality; variable domains neutralize the virus and constant domains $(\mathrm{Fc})$ engage the host immune system ${ }^{3}$. In humanized mice, Fc interactions lead to accelerated clearance of viruses and infected cells ${ }^{10}$. bNAb administration to macaques infected with chimeric simian and human immunodeficiency viruses (SHIV) is associated with $\mathrm{CD}^{+} \mathrm{T}$ cell-dependent lasting control in a fraction of the treated animals ${ }^{11}$. In humans, bNAb monotherapy was associated with increased $\mathrm{T}$ cell responses in 9 of 12 individuals; however this occurred after rebound viremia in all but 3 individuals ${ }^{12}$. Whether bNAb therapy has a positive impact on HIV-1-specific $\mathrm{T}$ cell immune responses in infected humans with prolonged suppression during ART interruption has not been determined.

In a phase $1 \mathrm{~b}$ clinical trial, individuals who were infected with HIV-1 and on ART were infused with a combination of two bNAbs, 3BNC117 and 10-1074, at 0, 3 and 6 weeks (Fig. 1a) 4 $^{4}$ ART was interrupted $2 \mathrm{~d}$ after the first antibody infusion. Nine bNAb-infused individuals harboring viruses sensitive to both bNAbs maintained viral suppression for at least 15 weeks following analytical treatment interruption (ATI) (Extended Data Fig. 1a,b) ${ }^{4}$.

Individuals who were infected with HIV-1 and on ART show stable or decreasing levels of HIV-1-specific $\mathrm{CD}^{+}$and $\mathrm{CD} 4^{+} \mathrm{T}$ cell responses over time ${ }^{13-15}$. To determine whether the combination of bNAb treatment and ATI was associated with alterations of CD8 ${ }^{+}$ and $\mathrm{CD} 4^{+} \mathrm{T}$ cell responses to HIV-1, we analyzed the peripheral blood of the nine individuals on bNAb + ATI at baseline (week -2) and during bNAb-mediated suppression (weeks 6/7, 12 and 18; Extended Data Fig. 1b; week 18 samples were limited to seven individuals). Peripheral blood mononuclear cells (PBMCs) were stimulated with an HIV-1 Consensus B Gag peptide pool. CD8 ${ }^{+} \mathrm{T}$ cells were analyzed for expression of interferon (IFN) $-\gamma$, tumor necrosis factor (TNF)- $\alpha$, macrophage inflammatory protein (MIP) $1-\beta$ and the degranulation marker CD107A; $\mathrm{CD} 4^{+} \mathrm{T}$ cells were analyzed for expression of IFN- $\gamma$, TNF- $\alpha$, interleukin (IL)-2 and CD40L (Supplementary Table 1 and Supplementary Fig. 1a-c).

In line with previous reports ${ }^{13-15}$, anti-HIV-1 $\mathrm{T}$ cell responses in individuals on long-term viral suppression by ART alone remained stable over time (Extended Data Fig. 2a,b). In contrast, the frequency of antigen-specific CD8 ${ }^{+}$T cells expressing IFN- $\gamma$, TNF- $\alpha$, MIP1- $\beta$ and/or CD107A increased significantly in all nine individuals receiving bNAbs during ATI after 6/7 weeks (Fig. 1b and Extended Data Fig. 3a). Of note, bNAb plasma levels were highest at this time point ${ }^{4}$ (Extended Data Fig. 1b). $\mathrm{CD}^{+} \mathrm{T}$ cell responses

'Research Centre of the Centre Hospitalier de I'Université de Montréal (CRCHUM), Montreal, QC, Canada. Université de Montréal, Montreal, QC, Canada. ${ }^{3}$ Consortium for HIV/AIDS Vaccine Development (CHAVD), La Jolla, CA, USA. ${ }^{4}$ Laboratory of Molecular Immunology, The Rockefeller University, New York, NY, USA. ${ }^{5}$ Laboratory of Experimental Immunology, Institute of Virology, Faculty of Medicine and University Hospital Cologne, University of Cologne, Cologne, Germany. ${ }^{6}$ Department I of Internal Medicine, Faculty of Medicine and University Hospital Cologne, University of Cologne, Cologne, Germany. ${ }^{7}$ German Center for Infection Research (DZIF), Partner Site Bonn-Cologne, Cologne, Germany. ${ }^{8}$ Center for Molecular Medicine Cologne, University of Cologne, Cologne, Germany. ${ }^{9}$ Present address: Perelman School of Medicine, University of Pennsylvania, Philadelphia, PA, USA. ${ }^{10}$ Present address: Department of Internal Medicine, Columbia University Medical Center, New York, NY, USA. "These authors contributed equally: Michel C. Nussenzweig, Daniel E. Kaufmann. *e-mail: nussen@mail.rockefeller.edu; daniel.kaufmann@umontreal.ca 


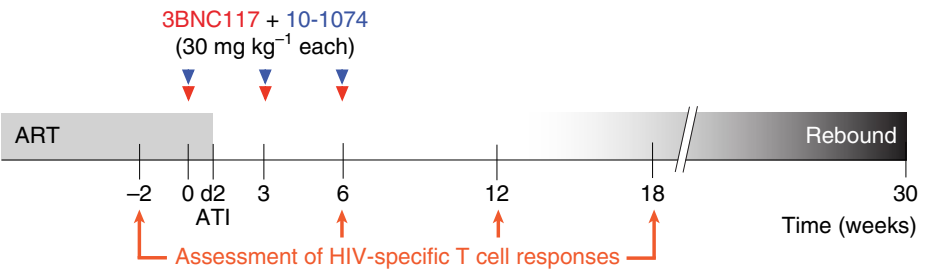

b
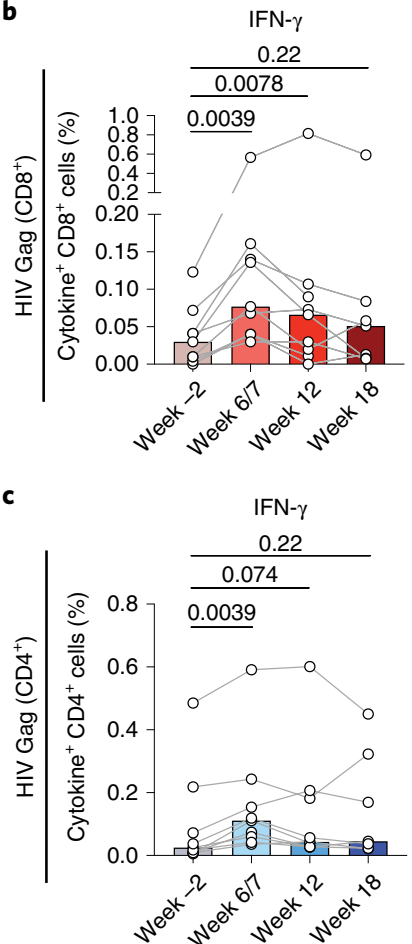
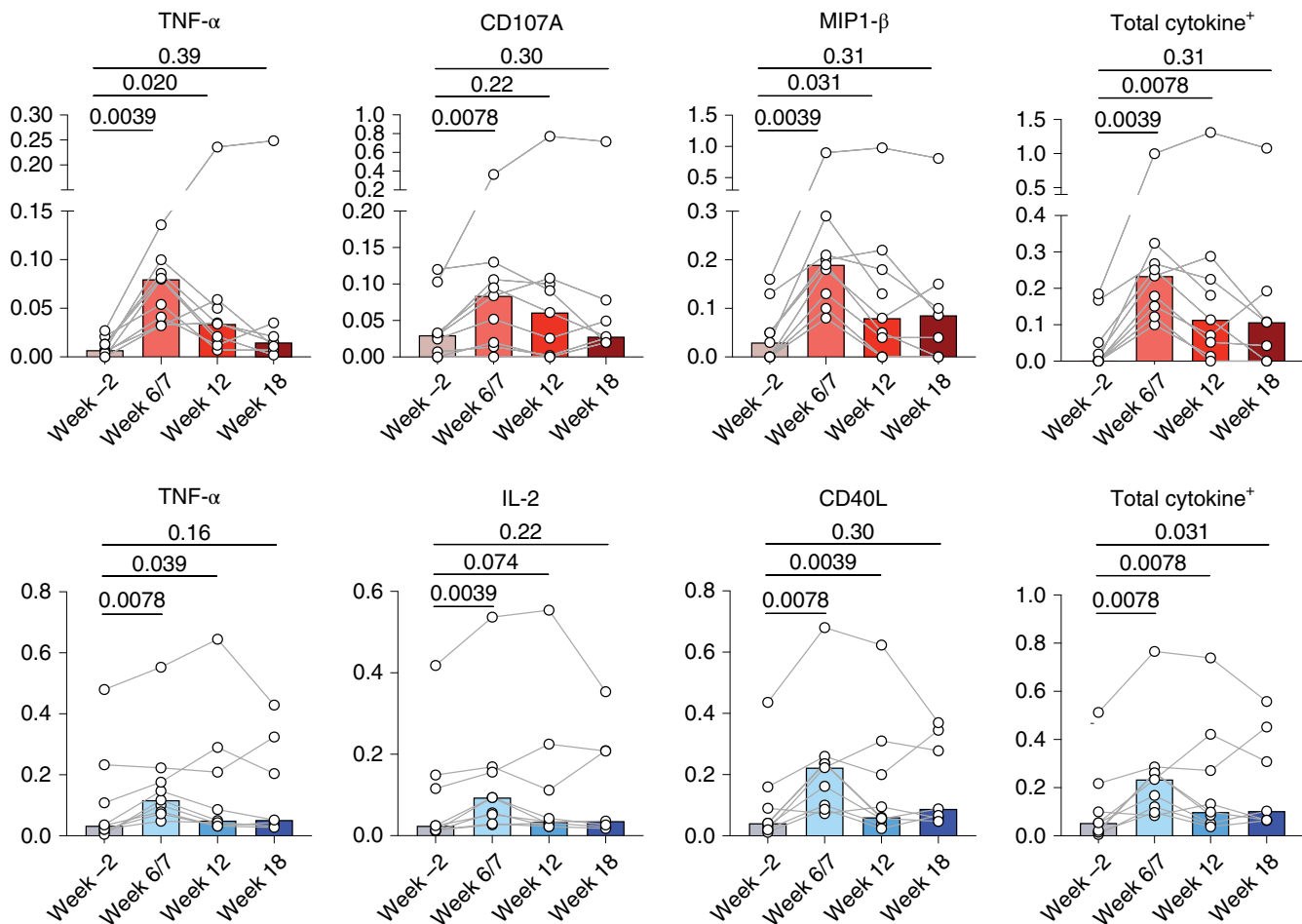

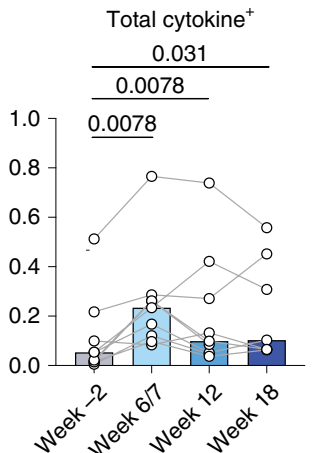

Fig. 1 | Increased frequency of Gag-specific T cells during ATI in bNAb-treated individuals. a, Study design. b,c, Net frequency of cytokine ${ }^{+}$CD $8^{+}$ (b) or CD4 ${ }^{+}$cells (c) after Gag stimulation at weeks $-2,6 / 7,12$ and 18. Total cytokine ${ }^{+}$cells include cells that express at least one cytokine and effector function upon Gag stimulation (CD107A, IFN- $\gamma$, MIP1- $\beta$ and/or TNF- $\alpha$ for CD8 ${ }^{+}$; CD4OL, IFN- $\gamma$, IL-2 and/or TNF- $\alpha$ for CD4+). Net value was calculated by subtracting the frequency of cytokine ${ }^{+}$cells detected in a DMSO control. Bars show median values. Symbols represent biologically independent samples from $n=9$ (weeks $-2,6 / 7$ and 12) and $n=7$ (week 18) bNAb-treated individuals with suppressed viral load during ATI (week 18 sample was not available for individual 9244 and individual 9242 reinitiated ART after viral rebound at week 15). Lines connect data from the same donor. $P$ values comparing responses at week 6/7,12 or 18 versus baseline (week -2) were calculated using a paired two-tailed Wilcoxon test.

decreased by week 12 in six individuals but remained significantly elevated for IFN- $\gamma$, TNF- $\alpha$ and MIP1- $\beta$ when compared to baseline. At week 18 , when antibody levels were $2-3$ orders of magnitude below the week 6/7 peak, $\mathrm{CD}^{+} \mathrm{T}$ cell responses were similar to week 12, but interpretation of these data was limited by the small sample size (Fig. 1b).

$\mathrm{CD} 4^{+} \mathrm{T}$ cells expressing IFN- $\gamma, \mathrm{CD} 40 \mathrm{~L}, \mathrm{TNF}-\alpha$ and/or IL-2 in response to Gag also increased significantly between baseline and week 6/7 in eight bNAb + ATI individuals (Fig. 1c). When measured individually, only CD $40 \mathrm{~L}$ and TNF- $\alpha$ remained significantly elevated at week 12 and no responses were significantly elevated at week 18. However, the total frequency of cytokine ${ }^{+} \mathrm{CD} 4^{+} \mathrm{T}$ cells (percentage of cells positive for one or more cytokines or functional markers) was above baseline at all time points tested (Fig. 1c). In contrast, cytomegalovirus (CMV) pp65-specific T cell responses remained unchanged (Extended Data Fig. 4a,b), suggesting that the increased $\mathrm{T}$ cell immunity in bNAb + ATI individuals was specific to $\mathrm{HIV}-1$. In summary, $\mathrm{CD}^{+}$and $\mathrm{CD}^{+} \mathrm{T}$ cell responses to $\mathrm{Gag}$ were most prominent at week $6 / 7$ but remained elevated for weeks after the last antibody dose in individuals who remained suppressed while receiving bNAbs during ATI.
Two additional individuals recruited to the study harbored antibody-resistant viruses and showed early rebound after ATI (9245 and 9251, Extended Data Fig. 5a,b) ${ }^{4}$. Gag-specific T cell responses in both participants were analyzed at baseline, week $6 / 7$ and week 11 or 12 after reinitiation of ART. Where the frequency of cytokine $^{+}$cells for $\mathrm{CD}^{+}$and $\mathrm{CD}^{+}$increased for individual 9245, the responses decreased for 9251 (Extended Data Fig. 5c), consistently with rebound viremia being sufficient to increase $\mathrm{CD}^{+} \mathrm{T}$ cell responses in some individuals ${ }^{16}$.

Polyfunctional HIV-1-specific $\mathrm{CD}^{+} \mathrm{T}$ cells have been associated with enhanced HIV-1 control ${ }^{9,17}$, whereas other studies reported superior antiviral functions of MIP1- $\beta$ monofunctional cells ${ }^{18}$. To examine Gag-specific T cells in bNAb + ATI individuals for polyfunctional responses, we performed coexpression analysis using Boolean gating. Gag-specific CD $8^{+}$T cells coexpressing IFN- $\gamma$, TNF- $\alpha$, MIP1- $\beta$ and CD107A were significantly increased at weeks $6 / 7$ and 12 after receiving bNAb therapy (Fig. 2a). However, the greatest absolute increase in $\mathrm{CD}^{+} \mathrm{T}$ cell responses to $\mathrm{Gag}$ was associated with expansion of MIP1- $\beta^{+}$single-positive cells (Fig. 2a). In addition, the frequency of CD $4^{+}$T cells expressing IFN- $\gamma$ or CD40L alone or in combination with other functions and IL-2/TNF- $\alpha$-double 

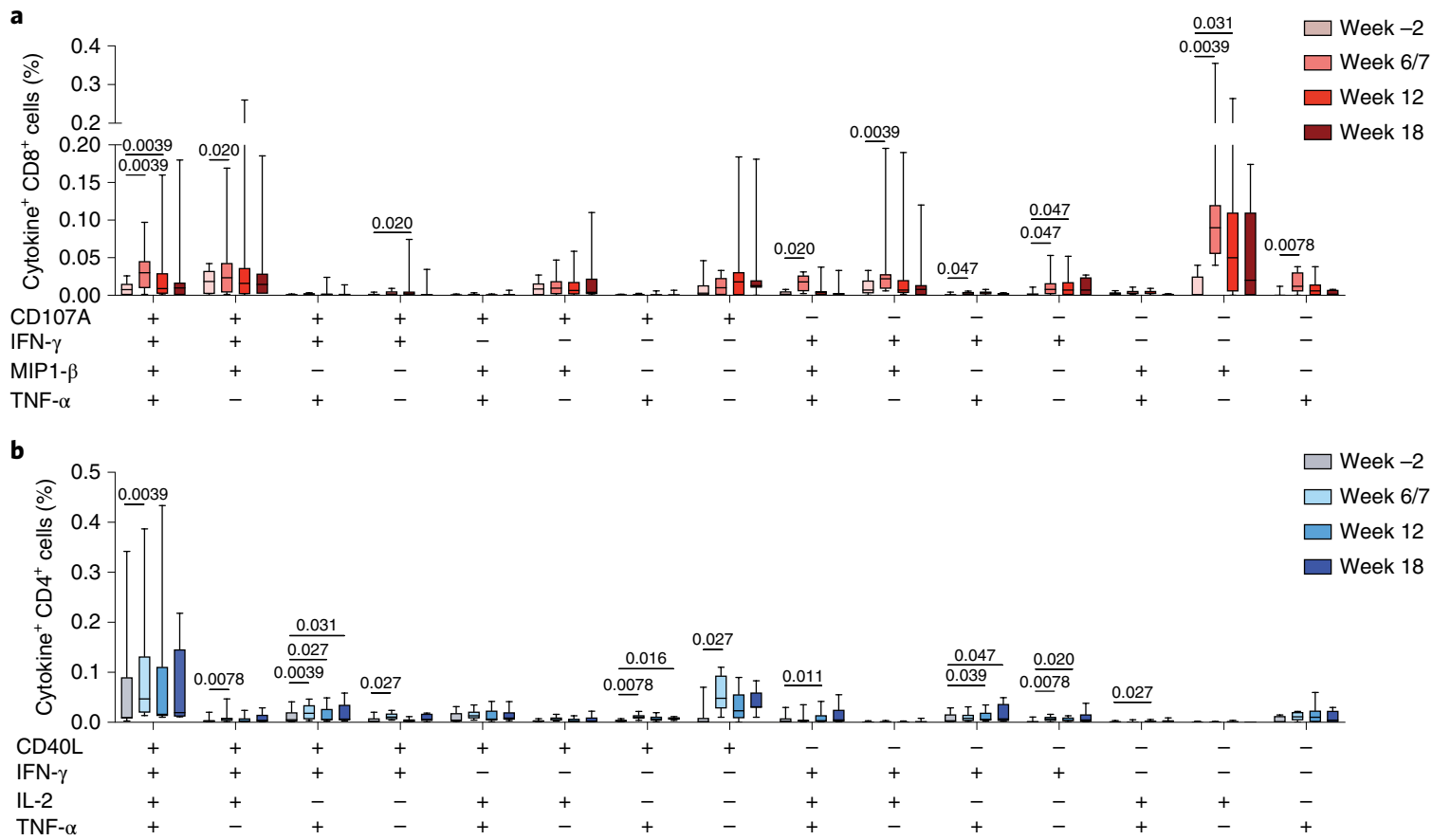

Fig. 2 | Polyfunctionality of Gag-specific T cells. T cell cytokine coexpression after HIV-1 Gag peptide pool stimulation was evaluated in bNAb + ATI individuals by ICS and analyzed using combination gates. a, Coexpression of CD107A, IFN- $\gamma$, MIP1- $\beta$ and TNF- $\alpha$ in CD8+ T cells. b, Coexpression of CD40L, IFN- $\gamma$, IL-2 and TNF- $\alpha$ in CD4+ T cells. Box-and-whisker plots show median values (line), 25th to 75th percentiles (box outline) and minimum and maximum values (whiskers); $n=9$ (weeks $-2,6 / 7$ and 12) and $n=7$ (week 18) biologically independent samples from bNAb-treated individuals with suppressed viral load during ATI. P values comparing responses at week 6/7, 12 or 18 versus baseline (week -2 ) were calculated using a paired two-tailed Wilcoxon test.

positive cells was also increased (Fig. 2b). Thus, several subsets of Gag-specific mono- or polyfunctional $\mathrm{CD}^{+}$and $\mathrm{CD}^{+} \mathrm{T}$ cells were augmented at weeks $6 / 7$ and 12 compared to baseline for bNAbtreated individuals (Fig. 2a,b).

Activation-induced marker (AIM) assays give a broader overview of the total peptide-reactive $\mathrm{T}$ cell response and identify cells without cytokine expression or expressing cytokines that are challenging to detect by intracellular cytokine staining (ICS $)^{19,20}$. We therefore used the AIM assay as an alternative, cytokine-independent method to confirm our findings obtained by ICS. $\mathrm{CD}^{+}$or $\mathrm{CD}^{+} \mathrm{AIM}^{+}$cells were identified as $\mathrm{CD} 69^{+}$programmed death ligand $(\mathrm{PD}-\mathrm{L}) 1^{+}$or $\mathrm{CD}^{2} 9^{+} 4-1 \mathrm{BB}^{+}$or $\mathrm{PD}-\mathrm{L}^{+} 4-1 \mathrm{BB}^{+}$after Gag peptide pool stimulation (Supplementary Fig. 2 and Supplementary Table 2).

Similarly to ICS, we found increased Gag-specific $\mathrm{T}$ cell responses in seven $\left(\mathrm{CD}^{+}\right)$or six $\left(\mathrm{CD} 4^{+}\right)$out of nine bNAb + ATI individuals at week 12 compared to baseline (Fig. 3a,b). As expected ${ }^{19}$, the frequency of Gag-specific $\mathrm{CD} 4^{+}$and $\mathrm{CD}^{+} \mathrm{T}$ cells was higher in the AIM assay but correlated with ICS (Fig. $3 c, d, r=0.64$ ). We did not detect changes in human leukocyte antigen (HLA)-DR ${ }^{+} \mathrm{CD} 38^{+}$or programmed cell death (PD)- $1^{+}$cells within $\mathrm{AIM}^{+}$Gag-specific T cell responses at week 12 versus baseline (Extended Data Fig. 6).

We further used the AIM assay to investigate responses to less immunodominant HIV-1 antigens with expected lower frequencies than Gag. In contrast to Gag, we did not find a significant increase in HIV-1-specific T cell responses directed against HIV-1 Pol, Nef, gp120 or gp41 at the cohort level (Fig. 3e). Nevertheless, enhanced $\mathrm{CD}^{+}$and/or $\mathrm{CD} 4^{+} \mathrm{T}$ cell responses to these HIV-1 proteins were noted in several individuals at week 12 compared to week -2, including against gp120 and gp41 (Extended Data Fig. 7a,b). Specifically, the two individuals with controlled viremia beyond 30 weeks showed increased $\mathrm{CD}^{+}$and $\mathrm{CD}^{+}$responses to nearly all HIV-1 antigens tested at week 12 (Extended Data Fig. 7a-c, participants 9254 and 9255). This was not seen in individuals who rebounded before week 26 after ATI (Extended Data Fig. 7a-c, participants 9241, 9242, 9243, 9244, 9246, 9247 and 9252). However, the association between prolonged control and breadth in these two individuals is anecdotal. Larger studies will be required to understand the precise relationship between prolonged control, bNAb therapy and enhanced breadth of $\mathrm{T}$ cell immunity.

To determine whether the increased HIV-1 Gag-specific T cell responses were directed against pre-existing or new peptide epitopes, we stimulated PBMCs with a peptide library spanning the entire HIV Gag protein Consensus B sequence (Supplementary Table 3) and compared IFN- $\gamma$ responses before and after ATI for the nine $\mathrm{bNAb}+\mathrm{ATI}$ individuals. IFN- $\gamma$ ELISpot responses were detectable for six study participants (Fig. 4a-d, Extended Data Fig. 8 and Supplementary Table 4). Four individuals from these six (9244, 9246, 9252 and 9255) broadened the IFN- $\gamma$ ELISpot response to Gag during ATI (Fig. 4a-d and Extended Data Fig. 8f). Overall, $41 \%$ ( 9 of 22) of the detectable responses in these six individuals at week 12 were directed against Gag epitopes that did not induce a detectable response at baseline (new responses: red dots and section, Fig. $4 \mathrm{e}, \mathrm{f}$ ). In contrast, none of the Gag responses detected at baseline were lost by week 12 . Finally, several individuals with detectable responses at week 12 had IFN- $\gamma$ ELISpot responses against the major homology region (peptide 69-76, Gag285-304; Fig. 4g), a highly conserved motif in the gag gene of all retroviruses ${ }^{21}$. Thus, the increased IFN- $\gamma$ responses that developed during bNAb therapy result from increased breadth and magnitude of detectable peptidespecific responses.

To determine whether the increased HIV-1-specific $\mathrm{T}$ cell response could eliminate HIV-1-infected cells in vitro, we performed HIV-1 viral inhibition assays ${ }^{22}$. CD $4^{+} \mathrm{T}$ cells from participants 9246 and 9252 at baseline were infected with HIV-1 $1_{\text {BaL }}$ and cultured either alone or in the presence of $\mathrm{CD}^{+} \mathrm{T}$ cells isolated from the same individuals before and after ATI (Extended Data Fig. 9a 
a

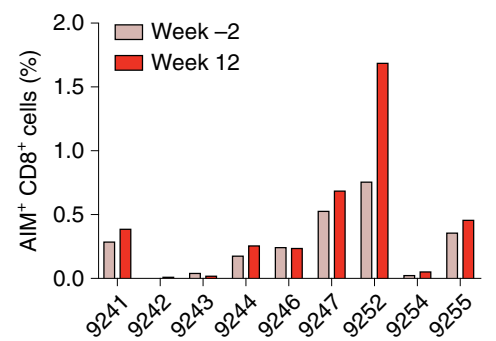

CD4 ${ }^{+}$

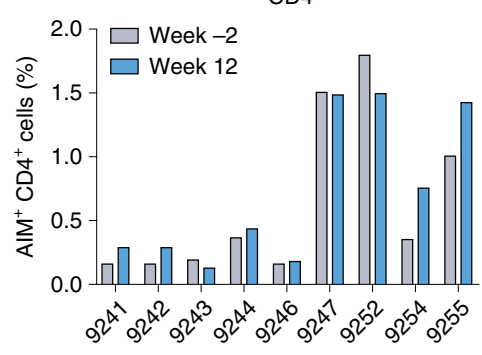

b

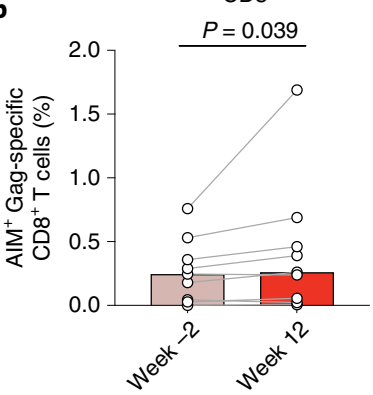

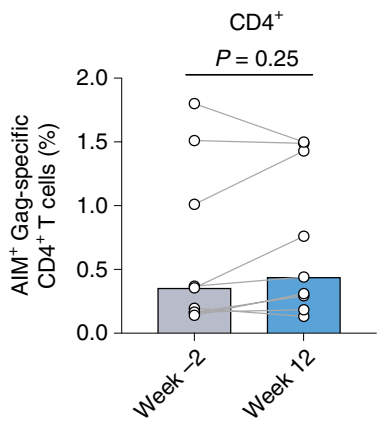

$\mathrm{CD}^{+}$

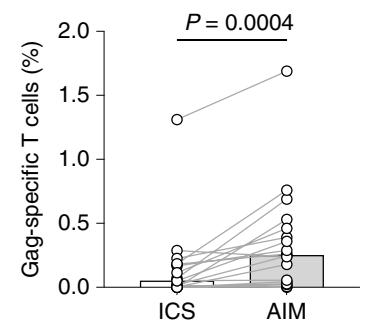

e
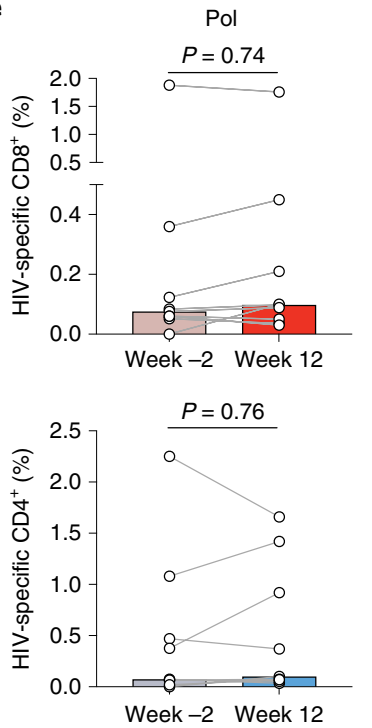

$\mathrm{CD}^{+}$

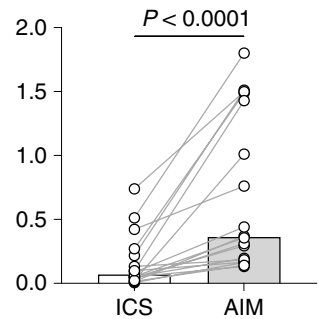

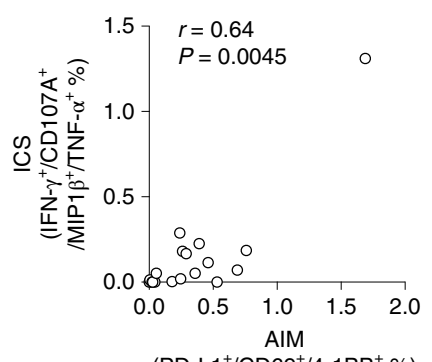

(PD-L1 $\left.{ }^{+} / \mathrm{CD}^{2} 9^{+} / 4-1 \mathrm{BB}^{+} \%\right)$

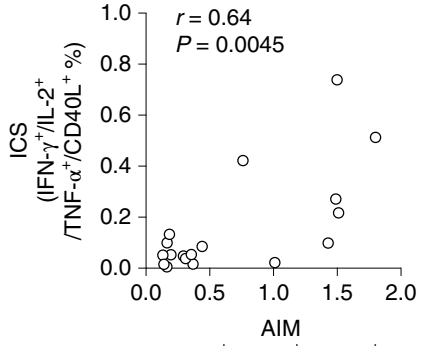

(PD-L1 ${ }^{+} / \mathrm{CD} 9^{+} / 4-1 \mathrm{BB}^{+} \%$ )
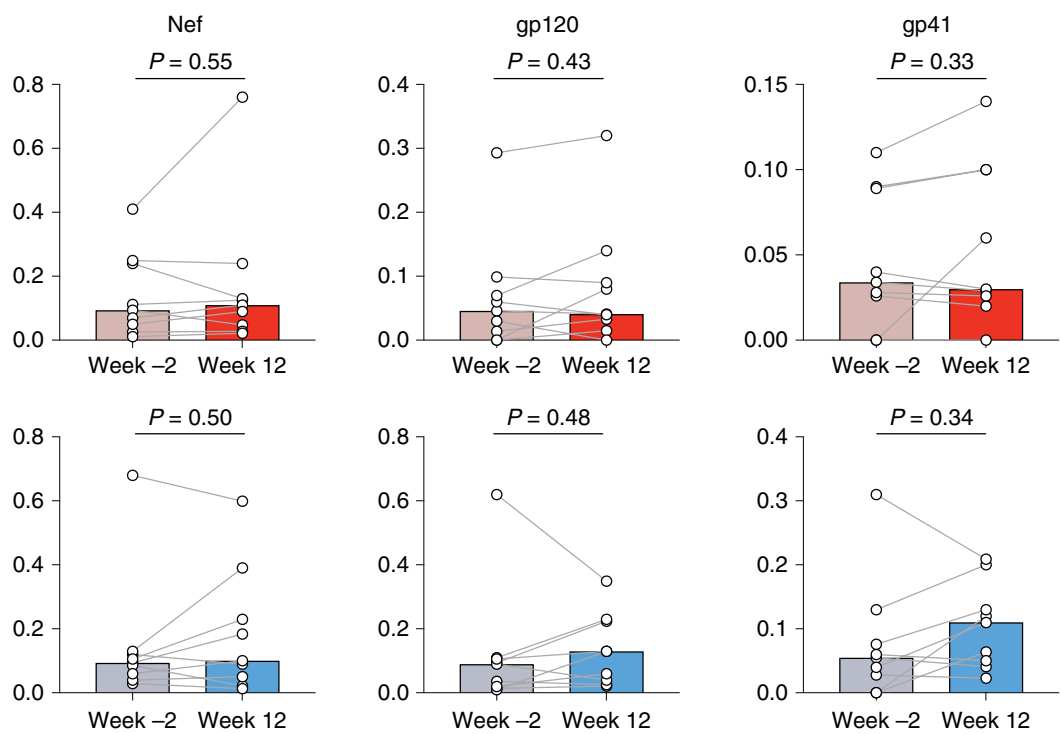

Fig. 3 AIM assay evaluation of T cell responses to multiple HIV-1 antigens. $\mathrm{AIM}^{+} \mathrm{T}$ cells include cells that were $\mathrm{PD}-\mathrm{L} 1^{+} \mathrm{CD} 69^{+}$or $4-1 \mathrm{BB} \mathrm{CD}^{+} 69^{+}$or PD-L1+4-1BB+. a, Net frequency of HIV-1 Gag-specific AIM+CD8+ (left, red) and CD4+ T cells (right, blue) for each bNAb + ATI individual. Net frequency of the Gag-stimulated condition was calculated by subtracting the frequency detected in a DMSO control. b, Comparison of net frequency HIV-1 Gagspecific AIM+CD8+ (left, blue) and CD4+ T cells (right, red) at week -2 and week 12 . Symbols represent biologically independent samples from $n=9$ bNAb + ATI individuals. Lines connect data from the same donor. Bars show median values. c, Comparison of the frequency of Gag-specific CD8 ${ }^{+}$or CD4+ T cells identified by AIM assay or ICS. The or-gate strategy was used for both assays. Symbols represent biologically independent samples from $n=9$ bNAb + ATI individuals (samples obtained at week -2 and 12 for each individual were included for comparison). Lines connect data from the same donor and time point. d, Relationship between the frequency of Gag-specific CD8 ${ }^{+}$and CD4+ T cell responses identified either by AIM assay or ICS. Symbols represent biologically independent samples from $n=9$ bNAb + ATI individuals (samples obtained at week -2 and 12 for each individual were included for comparison). Association was determined by Spearman correlation. e, Net frequency of HIV-1 Pol, Nef, gp120 or gp41-specific CD8+ (upper graphs) or CD4+ T cells (lower graphs) identified by AIM assay in bNAb + ATI individuals at week -2 and week 12 . Symbols represent biologically independent samples from $n=9$ bNAb + ATI individuals. Lines connect data from the same donor. Median values are shown as bars. $P$ values indicated in $\mathbf{b}, \mathbf{c}, \mathbf{e}$ were calculated by a paired two-tailed Wilcoxon test.

and Supplementary Table 5). Participant 9252 showed increased suppression of $\mathrm{HIV}-1_{\mathrm{BaL}}$ in vitro at week 12 compared to baseline (Extended Data Fig. 9b). However, 9246 was uninformative with no detectable impact on HIV-1 $1_{\mathrm{BaL}}$ outgrowth at baseline or week 12 (Extended Data Fig. 9b). Given the importance of HIV-1-specific
$\mathrm{CD}^{+} \mathrm{T}$ cells in controlling viral replication, we also examined rebound viruses for mutations in HIV-1 gag in the seven individuals who rebounded before week 30 . When compared to week -2 or 12, HIV-1 gag DNA from rebound plasma showed no consistent evidence for cytotoxic lymphocyte escape (Extended Data Fig. 10). 


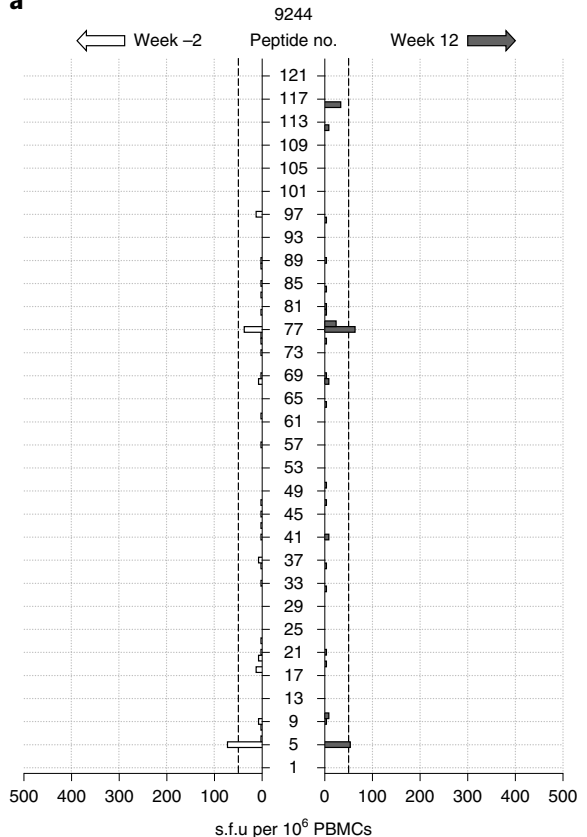

b

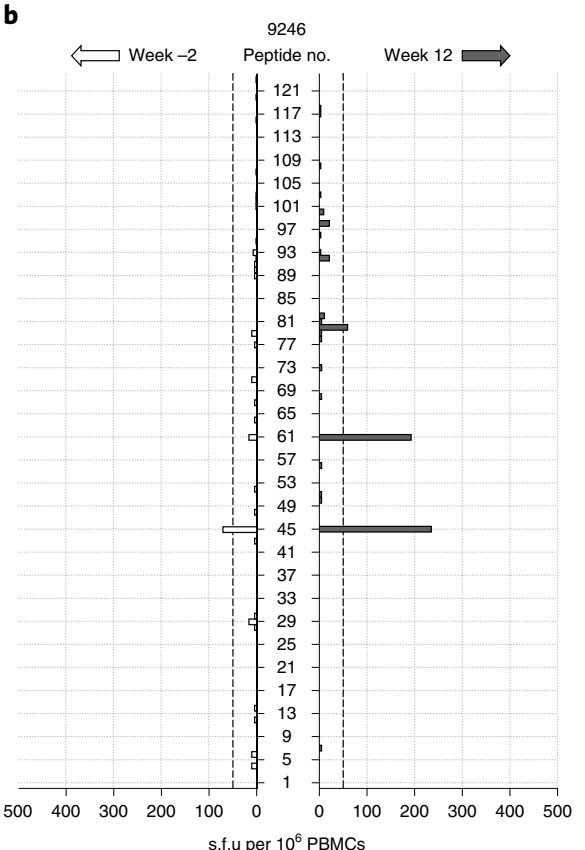

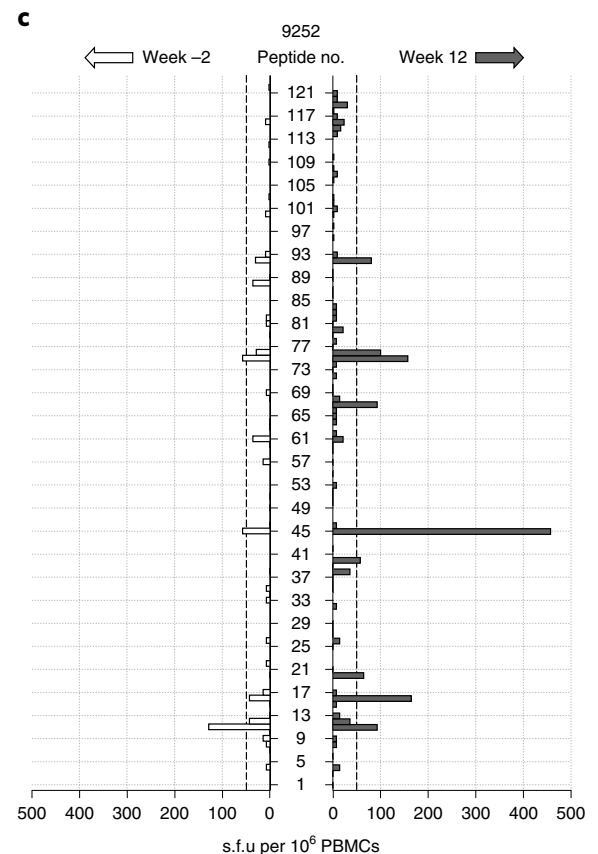

d

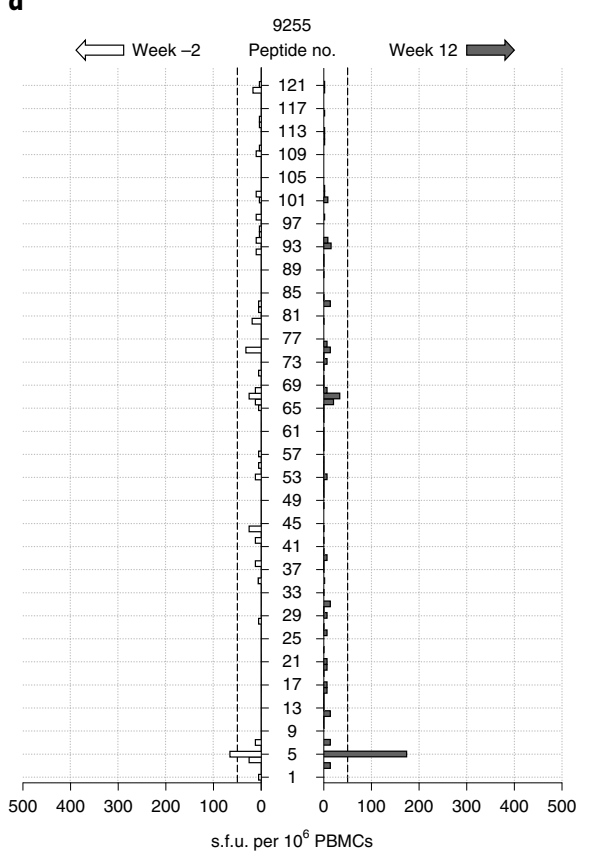

e

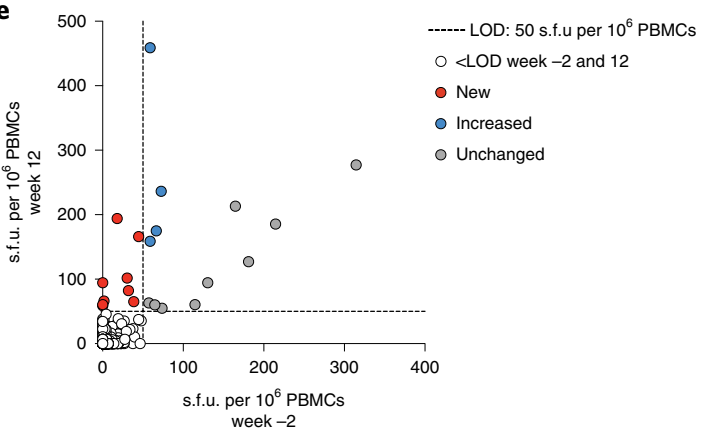

$\mathbf{f}$

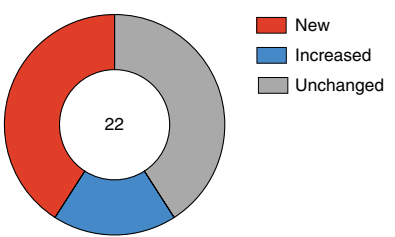

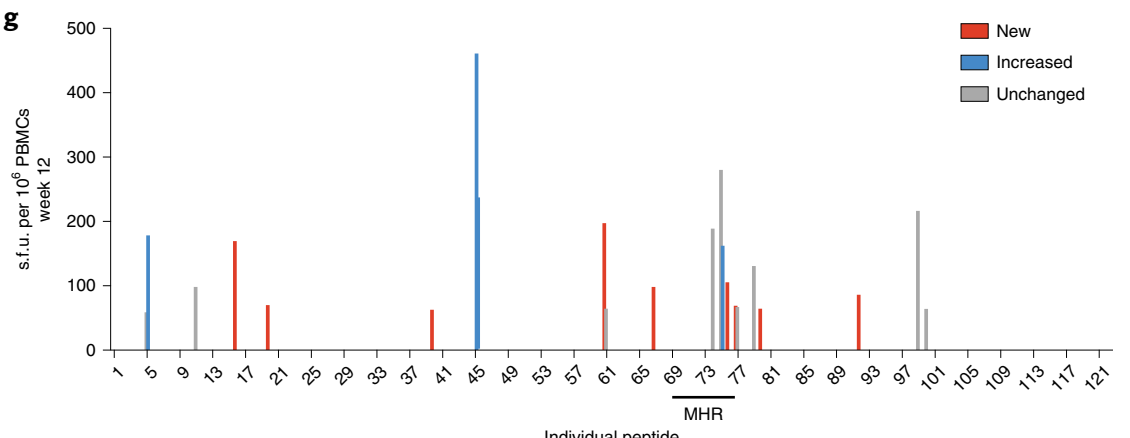

Individual peptide

Fig. 4 | Responses to HIV-1 Gag epitopes. PBMCs obtained at week -2 and 12 were evaluated for IFN- $\gamma$ ELISpot responses to 123 peptides spanning the entire HIV-1 Gag protein (Consensus Clade B sequence). a-d, Plots showing PBMC IFN- $\gamma$ ELISpot response calculated as spot-forming units (s.f.u.) per $10^{6}$ PBMCs for individuals with broadened IFN- $\gamma$ ELISpot response at week 12 (dark gray bars) compared to week -2 (white bars): $9244,9246,9252$ and 9255. e, PBMC IFN- $\gamma$ ELISpot responses at week -2 were plotted against week 12 responses for all nine individuals in the bNAb + ATI group. White symbols represent responses that were below the limit of detection (LOD) for both time points. Responses were considered as new (red symbols) if responses were undetectable for week -2 and detectable for week 12. Responses were considered as unchanged (light gray symbols) if number of spots did not differ by more than twofold between both time points. Responses were considered as increased (blue symbols) if number of spots for week -2 were increased by more than twofold for week 12 versus week -2. f, Doughnut chart depicting proportion of new, increased or unchanged IFN- $\gamma$ ELISpot responses within all detectable responses $(n=22)$ of the nine individuals at week 12 . g, Summary of detectable IFN- $\gamma$ ELISpot responses at week 12 for all nine bNAb study participants. The LOD of 50 s.f.u. per $10^{6}$ PBMCs is indicated as a dashed line in a-e.

HIV-1-specific T cell responses likely play a key role in spontaneous control of HIV-1 viremia in elite controllers ${ }^{7-9}$. However, most individuals exhibit partial control of viral replication as evidenced by suppression of initial peak viremia by $1-2$ orders of magnitude for prolonged periods of time before developing AIDS-defining clinical complications ${ }^{23}$. ART is highly effective in further suppressing viremia but fails to enhance virus-specific immunity possibly because of decreased viral antigen availability. 
In contrast, bNAb therapy in SHIV-infected rhesus macaques induces long-lasting $\mathrm{CD}^{+} \mathrm{T}$ cell-mediated viral suppression in a subset of the animals ${ }^{11,24}$. Our data indicate that individuals who are infected with HIV-1, receiving bNAb therapy during ATI, show increased T cell immunity to HIV-1, including reactivity to Gag epitopes that were undetectable before bNAb administration. Specifically, we identified increased frequencies of MIP1- $\beta$-expressing $\mathrm{CD}^{+}$ $T$ cells, which have been associated with control of viremia ${ }^{18}$. However, notably, the observational nature of this trial does not allow the determination of whether the observed expansion of HIV-1-specific T cell responses in bNAb-treated humans contributes to viral control.

Previous clinical trials in individuals who are infected with HIV-1, who underwent ATI in the absence of immune intervention, showed increased HIV-1-specific T cell responses that coincided with plasma viral rebound, suggesting that this boost in antiviral immunity was induced by increased viral replication ${ }^{16,25}$. The increased $\mathrm{T}$ cell responses in individual 9245 are consistent with these observations (Extended Data Fig. 5). In contrast, our results demonstrate increased HIV-1 Gag-specific $\mathrm{CD}^{+}$and $\mathrm{CD}^{+}{ }^{+} \mathrm{T}$ cell immunity in bNAb + ATI individuals at a time when bNAbs maintained viral suppression. At least two mechanisms could account for the association of bNAb treatment with increased $\mathrm{T}$ cell responses. One possibility is that ART interruption in the presence of antibodies results in production of bNAb-HIV-1 immune complexes that activate antigen-presenting dendritic cells and enhance their antigen-presenting and cross-presenting capabilities to produce a vaccinal effect ${ }^{3,26}$. A second nonexclusive possibility is that the augmented $\mathrm{CD}^{+} \mathrm{T}$ cell response is driven by increased low-grade viral replication and antigen availability in tissues that we have not been able to assay during overt viremia suppression by bNAbs. While the underlying mechanism of the observed increased T cell immunity remains to be determined, a potentially important advantage of bNAb + ATI treatment compared to ATI alone, standard ART or $\mathrm{T}$ cell vaccination is that the immune system is stimulated with the individual's own virus while circulating viremia is suppressed. Whether the same effects will be seen in individuals who receive bNAbs during ART and whether the increased T cell responses are sufficient to help control infection remains to be determined.

\section{Online content}

Any methods, additional references, Nature Research reporting summaries, source data, extended data, supplementary information, acknowledgements, peer review information; details of author contributions and competing interests; and statements of data and code availability are available at https://doi.org/10.1038/s41591019-0747-1.

Received: 24 June 2019; Accepted: 19 December 2019; Published online: 3 February 2020

\section{References}

1. Chun, T. W. et al. Presence of an inducible HIV-1 latent reservoir during highly active antiretroviral therapy. Proc. Natl Acad. Sci. USA 94, 13193-13197 (1997).

2. Finzi, D. et al. Identification of a reservoir for HIV-1 in patients on highly active antiretroviral therapy. Science 278, 1295-1300 (1997).
3. Caskey, M., Klein, F. \& Nussenzweig, M. C. Broadly neutralizing anti-HIV-1 monoclonal antibodies in the clinic. Nat. Med. 25, 547-553 (2019).

4. Mendoza, P. et al. Combination therapy with anti-HIV-1 antibodies maintains viral suppression. Nature 561, 479-484 (2018).

5. Koup, R. A. et al. Temporal association of cellular immune responses with the initial control of viremia in primary human immunodeficiency virus type 1 syndrome. J. Virol. 68, 4650-4655 (1994).

6. Goonetilleke, N. et al. The first $\mathrm{T}$ cell response to transmitted/founder virus contributes to the control of acute viremia in HIV-1 infection. J. Exp. Med. 206, 1253 (2009).

7. Rosenberg, E. S. et al. Vigorous HIV-1-specific $\mathrm{CD} 4^{+} \mathrm{T}$ cell responses associated with control of viremia. Science 278, 1447-1450 (1997).

8. Pereyra, F. et al. Genetic and immunologic heterogeneity among persons who control HIV infection in the absence of therapy. J. Infectious Dis. 197, 563-571 (2008).

9. Betts, M. R. et al. HIV nonprogressors preferentially maintain highly functional HIV-specific CD8 ${ }^{+}$T cells. Blood 107, 4781-4789 (2006).

10. Lu, C.-L. et al. Enhanced clearance of HIV-1-infected cells by broadly neutralizing antibodies against HIV-1 in vivo. Science 352, 1001-1004 (2016).

11. Nishimura, Y. et al. Early antibody therapy can induce long-lasting immunity to SHIV. Nature 543, 559-563 (2017).

12. Scheid, J. F. et al. HIV-1 antibody 3 BNC117 suppresses viral rebound in humans during treatment interruption. Nature 535, 556-560 (2016).

13. Achenbach, C. J. et al. Effect of therapeutic intensification followed by HIV DNA prime and rAd5 boost vaccination on HIV-specific immunity and HIV reservoir (EraMune 02): a multicentre randomised clinical trial. Lancet HIV 2, e82-e91 (2015).

14. Prebensen, C. et al. Immune activation and HIV-specific T cell responses are modulated by a cyclooxygenase-2 inhibitor in untreated HIV-infected individuals: an exploratory clinical trial. PLoS ONE 12, e0176527 (2017).

15. Gray, C. M. et al. Frequency of class I HLA-Restricted Anti-HIV CD8+ $\mathrm{T}$ cells in individuals receiving highly active antiretroviral therapy (HAART). J. Immunol. 162, 1780 (1999).

16. Oxenius, A. et al. Stimulation of HIV-specific cellular immunity by structured treatment interruption fails to enhance viral control in chronic HIV infection. Proc. Natl Acad. Sci. USA 99, 13747-13752 (2002).

17. Almeida, J. R. et al. Superior control of HIV-1 replication by CD8 ${ }^{+} \mathrm{T}$ cells is reflected by their avidity, polyfunctionality, and clonal turnover. J. Exp. Med. 204, 2473-2485 (2007).

18. Freel, S. A. et al. Phenotypic and functional profile of HIV-inhibitory CD8 ${ }^{+}$ $\mathrm{T}$ cells elicited by natural infection and heterologous prime/boost vaccination. J. Virol. 84, 4998-5006 (2010).

19. Reiss, S. et al. Comparative analysis of activation induced marker (AIM) assays for sensitive identification of antigen-specific $\mathrm{CD}^{+} \mathrm{T}$ cells. PLoS ONE 12, e0186998 (2017).

20. Morou, A. et al. Altered differentiation is central to HIV-specific $\mathrm{CD}^{+} \mathrm{T}$ cell dysfunction in progressive disease. Nat. Immunol. 20, 1059-1070 (2019).

21. Patarca, R. \& Haseltine, W. A. Similarities among retrovirus proteins. Nature 312, 496 (1984).

22. Saez-Cirion, A., Shin, S. Y., Versmisse, P., Barre-Sinoussi, F. \& Pancino, G. Ex vivo T cell-based HIV suppression assay to evaluate HIV-specific $\mathrm{CD}^{+}$ T cell responses. Nat. Protoc. 5, 1033-1041 (2010).

23. Piatak, M. J. et al. High levels of HIV-1 in plasma during all stages of infection determined by competitive PCR. Science 259, 1749-1754 (1993).

24. Borducchi, E. N. et al. Antibody and TLR7 agonist delay viral rebound in SHIV-infected monkeys. Nature 563, 360-364 (2018).

25. Fagard, C. et al. A prospective trial of structured treatment interruptions in human immunodeficiency virus infection. Arch. Intern. Med. 163, 1220-1226 (2003).

26. Bournazos, S. \& Ravetch, J. V. Fcy receptor pathways during active and passive immunization. Immunol. Rev. 268, 88-103 (2015).

Publisher's note Springer Nature remains neutral with regard to jurisdictional claims in published maps and institutional affiliations.

() The Author(s), under exclusive licence to Springer Nature America, Inc. 2020 


\section{Methods}

All information regarding material and methods can be found in the Life Sciences Reporting Summary.

Study design and participants. BNAb study participants were enrolled in an openlabel phase $1 \mathrm{~b}$ clinical trial at the Rockefeller University and University of Cologne and received three infusions with a combination of two bNAbs, 3BNC117 and 10-1074. ART was interrupted at day 2 after the first antibody infusion (ClinicalTrials.gov identifier: NCT02825797). Viral load was assessed every 1-2 weeks and ART was reinitiated when two consecutive measurements showed viral load of $>200$ copies per $\mathrm{ml}$. All individuals were infected with clade B HIV-1 $\left(\right.$ ref. $\left.{ }^{4}\right)$. Clinical data of all participants are shown in Extended Data Figs. 1a and 5a. Individuals on continuous ART were enrolled in an observational study at the Rockefeller University. Clinical data of all ART individuals are shown in Extended Data Fig. 2a. The studies were approved by the Rockefeller University and the University of Cologne Institutional Review Boards and written informed consent was obtained from all participants before study enrollment. Secondary use of samples was approved by the University of Montréal Hospital Institutional Review Board

Intracellular cytokine staining. PBMCs were thawed and rested for $2 \mathrm{~h}$ in RPMI 1640 medium (Gibco by Life Technologies) supplemented with 10\% FBS (Seradigm), penicillin and streptomycin (Gibco by Life Technologies) and HEPES (Gibco by Life Technologies) and stimulated with a HIV-1 Consensus B Gag peptide pool $\left(0.5 \mu \mathrm{g} \mathrm{ml}^{-1}\right.$ per peptide; NIH AIDS Reagent Program) or CMV pp65 peptide pool $\left(0.5 \mu \mathrm{g} \mathrm{ml}^{-1}\right.$ per peptide; JPT Peptide Technologies) for $6 \mathrm{~h}$ in the presence of anti-CD107A-BV786 (BD Biosciences), Brefeldin A (BD Biosciences) and monensin (BD Biosciences) at $37^{\circ} \mathrm{C}$ and $5 \% \mathrm{CO}_{2}$. DMSO-treated cells served as negative control. Cells were stained for aquavivid viability marker (Life Technologies) for $20 \mathrm{~min}$ at $4^{\circ} \mathrm{C}$ and surface markers $\left(30 \mathrm{~min}, 4^{\circ} \mathrm{C}\right)$, followed by intracellular detection of cytokines using the IC Fixation/Permeabilization kit (eBioscience) according to the manufacturer's protocol before acquisition at an LSRFortessa flow cytometer (BD Biosciences) (see Supplementary Table 1 for antibody staining panel).

Activation-induced marker assay. PBMCs were thawed, washed and cultured in 24 -well plates at a concentration of $10 \times 10^{6}$ cells per ml in RPMI 1640 supplemented with HEPES, penicillin and streptomycin and $10 \%$ human serum (Sigma). Cells were rested for $3 \mathrm{~h}$ and stimulated with $0.5 \mu \mathrm{g} \mathrm{ml}^{-1}$ per peptide of HIV-1 Consensus $B$ peptide pools spanning the entire protein for Gag, Nef, Pol, gp120 or gp41 (NIH AIDS Reagent Program) for $18 \mathrm{~h}$ at $37^{\circ} \mathrm{C}$ and $5 \% \mathrm{CO}_{2}$. Pools for gp 120 and gp41 were obtained by combining single Env peptides 1-123 (gp120) and 124-211 (gp41) (HIV-1 Consensus B Env Peptide Set). A DMSO-treated condition served as a negative control. Cells were stained for viability dye (aquavivid, Life Technologies) and surface markers $\left(30 \mathrm{~min}, 4^{\circ} \mathrm{C}\right.$ ) and cells were fixed using $2 \%$ paraformaldehyde before acquisition at a LSRII flow cytometer (BD Biosciences) (see Supplementary Table 2 for antibody staining panel). DMSO-treated cells served as negative controls and were used together with fluorescence minus one controls to set gates for analysis.

IFN- $\boldsymbol{\gamma}$ ELISpot. HIV Gag-specific IFN- $\boldsymbol{\gamma}$ responses were measured using an IFN- $\boldsymbol{\gamma}$ ELISpot assay as previously described ${ }^{27}$. The 96 -well hydrophobic polyvinylidene difluoride membrane-backed plates (Millipore) were pre-wetted with $35 \%$ ethanol for $45 \mathrm{~s}$, washed with PBS and coated overnight at $4{ }^{\circ} \mathrm{C}$ with anti-IFN- $\gamma$ capture antibody ( $3 \mu \mathrm{g} \mathrm{ml}^{-1}$ in PBS, clone NIB42, BD Biosciences). PBMCs were thawed, rested for $2 \mathrm{~h}$ and seeded into plates at $1-2 \times 10^{5}$ PBMCs per well in RPMI with $10 \%$ FBS supplemented with HEPES and penicillin and streptomycin. Cells were stimulated with 123 peptides spanning the entire HIV-1 Consensus B Gag protein $\left(10 \mu \mathrm{g} \mathrm{ml}^{-1}\right.$, NIH AIDS Reagent Program; see Supplementary Table 3 for all sequences) for $20 \mathrm{~h}$ at $37^{\circ} \mathrm{C}$ and $5 \% \mathrm{CO}_{2}$. Plates were washed with PBS-T (PBS and $0.05 \%$ Tween-20) and incubated with biotinylated anti-IFN- $\gamma$ antibody ( $0.5 \mu \mathrm{g} \mathrm{ml}^{-1}$ in PBS and 0.5\% BSA, clone 4S.B3; BD Biosciences) for $2 \mathrm{~h}$ at room temperature. Plates were washed with PBS-T and incubated with streptavidinalkaline-phosphatase conjugate (Bio-Rad Laboratories) (1:1,000 dilution in PBS and $0.5 \% \mathrm{BSA}$ ) for $1 \mathrm{~h}$ at room temperature. Spots were developed using an alkaline phosphatase conjugate substrate kit (Bio-Rad Laboratories) for $4 \mathrm{~min}$ and the reaction was stopped with tap water. Spots were counted using an Immunospot Analyzer Instrument (Cellular Technology). PBMCs incubated with medium alone served as negative controls and staphylococcal enterotoxin B-stimulated PBMCs $\left(0.5 \mu \mathrm{g} \mathrm{ml}^{-1}\right)$ as a positive control. The s.f.u. were calculated as number of spots in test wells minus the mean number of spots in medium control wells and normalized to s.f.u. per $10^{6}$ PBMCs. A response was considered positive if greater than 50 s.f.u. per $10^{6}$ PBMCs. Week -2 and week 12 samples from the same individual were assayed together in the same experiment.

In vitro viral inhibition assay. The capacity of $\mathrm{CD} 8^{+} \mathrm{T}$ cells to suppress $\mathrm{HIV}-1$ infection of autologous $\mathrm{CD} 4^{+} \mathrm{T}$ cells was evaluated using a previously described HIV-1 suppression assay ${ }^{22}$ with minor modifications. CD4 ${ }^{+} \mathrm{T}$ cells were isolated using negative magnetic bead selection (StemCell Technologies) from PBMCs, rested for $2 \mathrm{~h}$ and cultured in RPMI and 10\% FBS supplemented with PHA-L $\left(2 \mu \mathrm{g} \mathrm{ml}^{-1}\right.$; Sigma-Aldrich) and IL-2 (100 $\mathrm{U} \mathrm{ml}^{-1}$; StemCell Technologies) for $72 \mathrm{~h}$.
After $72 \mathrm{~h}, \mathrm{CD}^{+} \mathrm{T}$ cells were isolated from PBMCs using negative magnetic bead selection (StemCell Technologies), counted and rested for $2 \mathrm{~h}$ at $37^{\circ} \mathrm{C}$. Meanwhile, cultured $\mathrm{CD} 4^{+} \mathrm{T}$ cells were washed, counted and plated in U-bottom 96-well plates for infection with HIV-1 $1_{\text {BaI }}$ (NIH AIDS Reagent Program) using a multiplicity of infection of 0.015 : plates were first centrifuged at $1,200 \mathrm{~g}$ for $1 \mathrm{~h}$ at $22^{\circ} \mathrm{C}$ and then incubated for an additional hour at $37^{\circ} \mathrm{C}$. After infection, $\mathrm{CD} 4^{+} \mathrm{T}$ cells from different wells were pooled, washed three times and plated in U-bottom 96-well plates (50,000 cells per well) with $\mathrm{CD}^{+} \mathrm{T}$ cells at a $1: 1$ ratio in RPMI with $10 \%$ FBS supplemented with IL-2 $\left(100 \mathrm{U} \mathrm{ml}^{-1}\right)$. Uninfected CD4 ${ }^{+} \mathrm{T}$ cells were included as negative controls and infected $\mathrm{CD} 4^{+} \mathrm{T}$ cells cultured without $\mathrm{CD} 8^{+} \mathrm{T}$ cells served as $100 \%$ infectivity controls. At days 3,5 and 7 after infection, cells were stained with a viability dye (aquavivid, Life Technologies) and surface markers (30 min, $4{ }^{\circ} \mathrm{C}$ ), followed by intracellular detection of HIV-1 Gag (Beckman Coulter) using the IC Fixation/Permeabilization kit (eBioscience) according to the manufacturer's protocol (see Supplementary Table 5 for the antibody staining panel). All experiments were performed in duplicate or triplicate, depending on cell availability.

Sequencing and phylogenetic analysis. Gag sequences from latent reservoir viruses were obtained from $\mathrm{CD} 4^{+} \mathrm{T}$ cell genomic DNA by near-full length HIV-1 sequencing as previously described ${ }^{28}$. Gag sequences from rebound plasma were obtained by HIV-1 RNA extraction and single-genome amplification as previously described $^{29}$. In brief, HIV-1 RNA was extracted from plasma samples using the MinElute Virus Spin kit (Qiagen) followed by first-strand cDNA synthesis using SuperScript III reverse transcriptase (Invitrogen). The cDNA synthesis for plasma-derived HIV-1 RNA was performed using the antisense primer B5R2 5'-CAATCATCACCTGCCATCTGTTTTCCATA-3'. Gag was then amplified using the primer Gag5out 5'-TTGACTAGCGGAGGCTAGAAGG-3' and Gag3out $5^{\prime}$-GATAAAACCTCCAATTCCCCCTATC- $3^{\prime}$ in the first round and in the second round with nested primers Gag5in 5'-GAGAGATGGGTGCGAGAGCGTC-3' and Gag3in 5'-CTGCTCCTGTATCTAATAGAGC-3'. PCRs were performed using High Fidelity Platinum Taq (Invitrogen) and run at $94^{\circ} \mathrm{C}$ for $2 \mathrm{~min} ; 35$ cycles of $94^{\circ} \mathrm{C}$ for $15 \mathrm{~s}, 58^{\circ} \mathrm{C}$ for $30 \mathrm{~s}$ and $68^{\circ} \mathrm{C}$ for $3 \mathrm{~min}$; and $68^{\circ} \mathrm{C}$ for $15 \mathrm{~min}$. Secondround PCR was performed with $1 \mu \mathrm{l}$ of the PCR product from the first round as a template and High Fidelity Platinum Taq at $94^{\circ} \mathrm{C}$ for $2 \mathrm{~min} ; 45$ cycles of $94^{\circ} \mathrm{C}$ for $15 \mathrm{~s}, 58^{\circ} \mathrm{C}$ for $30 \mathrm{~s}$ and $68^{\circ} \mathrm{C}$ for $3 \mathrm{~min}$; and $68^{\circ} \mathrm{C}$ for $15 \mathrm{~min}$.

Amino acid alignments of intact $g a g$ sequences were obtained by using ClustalW v.2.1 (ref. ${ }^{30}$ ) under the BLOSUM cost matrix. Sequences with premature stop codons were excluded from all analyses. Maximum likelihood phylogenetic trees were then generated from these alignments using RAxML v.8.2.9 (ref. ${ }^{31}$ ) under the GTRGAMMA model with 1,000 bootstraps. To analyze changes between reservoir and rebound viruses, gag sequences were aligned at the amino-acid-level to a HXB2 reference using ClustalW v.2.1.

Data analysis. Flow cytometric data were analyzed using FlowJo v.10.5.0 for Mac. Statistical analyses were performed using GraphPad Prism v.8.0.1 for Mac using nonparametric tests. Pairwise comparisons were performed using the two-sided Wilcoxon matched-pairs signed rank test.

Reporting Summary. Further information on research design is available in the Nature Research Reporting Summary linked to this article.

\section{Data availability}

Sequences from all isolated viruses are available in GenBank, accession numbers MN750027 to MN750174. Other raw experimental data associated with the figures presented in the manuscript are available from the corresponding authors upon reasonable request. Study participant-related data not included in the paper may be subject to confidentiality obligations.

\section{References}

27. Pelletier, S. et al. Increased degranulation of natural killer cells during acute HCV correlates with the magnitude of virus-specific T cell responses. J. Hepatol. 53, 805-816 (2010).

28. Lu, C.-L. et al. Relationship between intact HIV-1 proviruses in circulating $\mathrm{CD} 4\left(^{+}\right) \mathrm{T}$ cells and rebound viruses emerging during treatment interruption. Proc. Natl Acad. Sci. USA 115, E11341-E11348 (2018).

29. Salazar-Gonzalez, J. F. et al. Deciphering human immunodeficiency virus type 1 transmission and early envelope diversification by single-genome amplification and sequencing. J. Virol. 82, 3952-3970 (2008).

30. Larkin, M. A. et al. Clustal W and Clustal X version 2.0. Bioinformatics 23, 2947-2948 (2007)

31. Stamatakis, A. RAxML version 8: a tool for phylogenetic analysis and post-analysis of large phylogenies. Bioinformatics 30, 1312-1313 (2014).

32. Gartner, S. et al. The role of mononuclear phagocytes in HTLV-III/LAV infection. Science 233, 215-219 (1986).

\section{Acknowledgements}

We thank the clinical staff in the Laboratory of Molecular Immunology at the Rockefeller University and the Division of Infectious Diseases at the University Hospital Cologne, 
as well as all study participants for their invaluable role in this project; D. Gauchat, P. St-Onge and the CRCHUM Flow Cytometry Platform and O. Debbeche and the CRCHUM BSL3 platform for technical assistance. The following reagents were obtained through the NIH AIDS Reagent Program, Division of AIDS, NIAID, NIH: Consensus B peptide pools for Gag (cat. no.12425), Pol (cat. no. 12438), Nef (cat. no. 12545), gp120 and gp41 (pools made using HIV-1 Consensus B Env Peptide Set, cat. no. 9480), Consensus B Gag Peptide Set (cat. no. 8117) and HIV-1 $1_{\text {BaL }}$ (cat. no. 510) from S. Gartner, M. Popovic and R. Gallo ${ }^{32}$. This study was supported by the Canadian Institutes for Health Research (grant nos. 152977 and 154049 to D.E.K), a Canada Foundation for Innovation Program Leader grant (no. 31756 to D.E.K); the FRQS AIDS and Infectious Diseases Network; the National Institutes of Health UM1 AI-100663 (CHAVI-ID) and AI-144462 (CHAVD); R01AI-129795 (M.C.N.); the Einstein-Rockefeller-CUNY Center for AIDS Research (1P30AI124414-01A1); BEAT-HIV Delaney grant UM1 AI-126620 (M.C.); and the Robertson Fund. We acknowledge grants from the Bill and Melinda Gates Foundation Collaboration for AIDS Vaccine Discovery, nos. OPP1092074 and OPP1124068 (M.C.N.). J.N. is supported by scholarships from the Quebec Health Research Fund (FRQS) and the Department of Microbiology, Immunology and Infectious Diseases, Université de Montréal. A.E.B. is the recipient of a CIHR Fellowship Award no. 152536. D.E.K is supported by a Merit Award of the Quebec Health Research Fund (FRQS). M.C.N. is an HHMI Investigator.

\section{Author contributions}

J.N., A.E.B., M.C.N. and D.E.K. designed the immunological studies; M.C., F.K. and M.C.N. designed the trial from which the samples were obtained; J.N., A.E.B., P.M., M.J.,
C.-L.L. and H.G. performed experiments; M.D. provided input on manuscript content and data representation; Y.Z.C. and A.L.B. contributed to recruitment and clinical assessments; I.S. coordinated and performed sample processing; J.N., M.C.N. and D.E.K. interpreted the data and wrote the paper with all co-authors' assistance; M.C.N. and D.E.K. provided supervision

\section{Competing interests}

There are patents on 3BNC117 (PTC/US2012/038400) and 10-1074 (PTC/US2013/ 065696) that list M.C.N. as an inventor. M.C.N. is a member of the Scientific Advisory Board of Frontier Bioscience. Gilead has the rights to develop the 3BNC117 and 10-1074 antibody combination for clinical use.

\section{Additional information}

Extended data is available for this paper at https://doi.org/10.1038/s41591-019-0747-1. Supplementary information is available for this paper at https://doi.org/10.1038/ s41591-019-0747-1.

Correspondence and requests for materials should be addressed to M.C.N. or D.E.K.

Peer review information Alison Farrell was the primary editor on this article and managed its editorial process and peer review in collaboration with the rest of the editorial team.

Reprints and permissions information is available at www.nature.com/reprints. 
a

\begin{tabular}{|c|c|c|c|c|c|c|c|c|c|c|c|c|c|c|c|}
\hline \multirow[b]{2}{*}{ ID } & \multirow[b]{2}{*}{ Age } & \multirow[b]{2}{*}{ Gender } & \multirow[b]{2}{*}{ Race } & \multicolumn{2}{|c|}{ Years since } & \multirow{2}{*}{$\begin{array}{c}\text { Uninterr. } \\
\text { ART } \\
\text { before ATI } \\
\text { (yrs) } \\
\end{array}$} & \multirow[b]{2}{*}{$\begin{array}{c}\text { ART at } \\
\text { screening }\end{array}$} & \multirow[b]{2}{*}{$\begin{array}{c}\text { Switched } \\
\text { ART }\end{array}$} & \multirow{2}{*}{$\begin{array}{c}\text { Reported } \\
\text { CD4 } \\
\text { nadir } \\
\end{array}$} & \multirow[b]{2}{*}{$\begin{array}{c}\text { HLA } \\
\text { alleles }\end{array}$} & \multirow{2}{*}{$\begin{array}{c}\mathrm{CD4} \\
\text { count } \\
\text { (d0) }\end{array}$} & \multicolumn{3}{|c|}{ HIV-1 RNA (cp/ml) } & \multirow{2}{*}{$\begin{array}{l}\text { Weeks to } \\
\text { viral } \\
\text { rebound }\end{array}$} \\
\hline & & & & $\begin{array}{c}\text { HIV-1 } \\
\text { dx }\end{array}$ & $\begin{array}{l}\text { first } \\
\text { ART }\end{array}$ & & & & & & & Ser & $\begin{array}{c}\text { Week } \\
-2 \\
\end{array}$ & do & \\
\hline 9241 & 40 & $\mathrm{M}$ & White/Hisp & 6 & 5 & 5 & $\begin{array}{l}\text { EVG/cobi/ } \\
\text { TDF/FTC }\end{array}$ & - & 500 & $\begin{array}{c}\text { A23,33; } \\
\text { B14,44; } \\
\text { C4,8 }\end{array}$ & 515 & $<20$ & $<20$ & $<20$ & 21 \\
\hline 9242 & 43 & $\mathrm{M}$ & White/Hisp & 3 & 3 & 2 & $\begin{array}{l}\text { EVG/cobi/ } \\
\text { TDF/FTC }\end{array}$ & - & 450 & $\begin{array}{c}\text { A24; } \\
\text { B35,39; } \\
\text { C4, } 7\end{array}$ & 654 & $<20$ & $<20$ & $<20$ & 15 \\
\hline 9243 & 29 & $\mathrm{M}$ & $\begin{array}{c}\text { Amer } \\
\text { Indian/Hisp }\end{array}$ & 5 & 5 & 5 & $\begin{array}{c}\text { RPV/TDF/ } \\
\text { FTC }\end{array}$ & $\begin{array}{c}\text { DTG/ } \\
\text { TDF/FTC }\end{array}$ & 350 & $\begin{array}{l}\text { A24,30; } \\
\text { B15,35; } \\
\text { C2,15 }\end{array}$ & 350 & $<20$ & $<20 \mathrm{D}$ & $<20 \mathrm{D}$ & 20 \\
\hline 9244 & 36 & M & $\begin{array}{c}\text { Amer } \\
\text { Indian/not } \\
\text { Hisp }\end{array}$ & 9 & 5 & 5 & $\begin{array}{l}\text { EVG/cobi/ } \\
\text { TAF/FTC }\end{array}$ & - & 730 & $\begin{array}{c}\mathrm{A} 1,3 ; \\
\mathrm{B} 44,51 ; \\
\mathrm{C} 5,15\end{array}$ & 1,110 & $<20$ & $<20$ & $<20$ & 21 \\
\hline 9246 & 30 & M & Black & 5 & 5 & 5 & $\begin{array}{l}\text { EVG/cobi/ } \\
\text { TAF/FTC }\end{array}$ & - & 500 & $\begin{array}{l}\text { A29,68; } \\
\text { B45,81; } \\
\text { C16,18 }\end{array}$ & 745 & $<20$ & $<20$ & $<20 \mathrm{D}$ & 19 \\
\hline 9247 & 31 & M & Black & 6 & 6 & 6 & $\begin{array}{l}\text { EVG/cobi/ } \\
\text { TAF/FTC }\end{array}$ & - & 600 & $\begin{array}{c}\text { A33,34; } \\
\text { B44,78; } \\
\text { C4,16 }\end{array}$ & 728 & $<20$ & $<20$ & $<20$ & 26 \\
\hline 9252 & 51 & $\mathrm{~F}$ & Black & 11 & 11 & 11 & $\begin{array}{c}\mathrm{EFV} / \mathrm{TDF} / \\
\mathrm{FTC}\end{array}$ & $\begin{array}{c}\text { DTG/ } \\
\text { TDF/FTC }\end{array}$ & 270 & $\begin{array}{l}\text { A2,66; } \\
\text { B39,78; } \\
\text { C12,16 }\end{array}$ & 598 & $<20$ & $<20$ & $<20$ & 22 \\
\hline 9254 & 48 & M & White & 21 & 21 & 21 & $\begin{array}{l}\text { EVG/cobi/ } \\
\text { TAF/FTC }\end{array}$ & 我 & 590 & $\begin{array}{c}\text { A1,29 } \\
\text { B38,44; } \\
\text { C12,16 }\end{array}$ & 860 & $<20$ & $<20$ & $<20$ & $>30$ \\
\hline 9255 & 30 & $\mathrm{M}$ & White & 5 & 4 & 4 & $\begin{array}{l}\text { EVG/cobi/ } \\
\text { TAF/FTC } \\
\end{array}$ & - & 779 & $\begin{array}{c}\mathrm{A} 3,25 \\
\text { B18,44; } \\
\text { C } 7,12 \\
\end{array}$ & 1360 & $<20$ & $\angle 20 \mathrm{D}$ & $<20$ & $>30$ \\
\hline
\end{tabular}

b

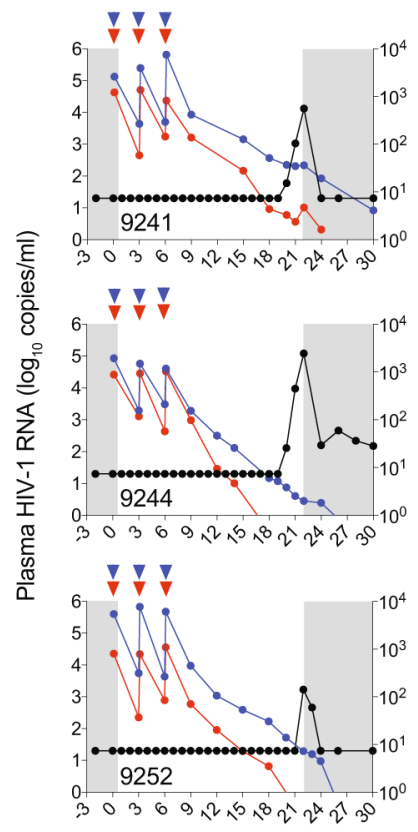

$\nabla \nabla \nabla$

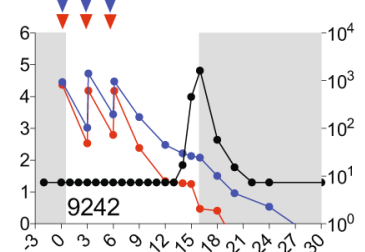

$\nabla \nabla \nabla$

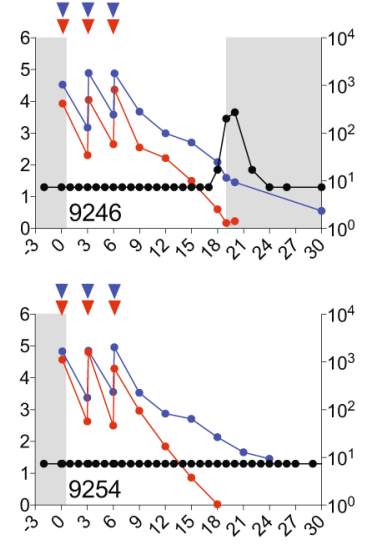

Weeks of ATI

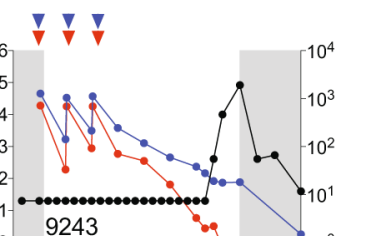

$9243, \quad 10^{\circ}$

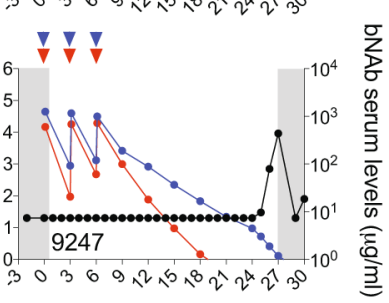

- $\nabla \nabla \nabla$

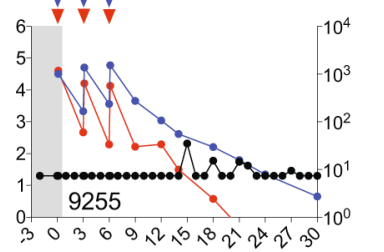

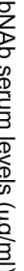

- Viral Load

- 3BNC117

- 10-1074

\begin{tabular}{l|l}
$\nabla$ 3BNC117 & $30 \mathrm{mg} / \mathrm{kg}$
\end{tabular}

\begin{tabular}{l|l}
$\nabla$ 10-1074 i.v. \\
on
\end{tabular}

on ART

Extended Data Fig. 1 | Study participant clinical characteristics. (a) Study participant demographics and baseline clinical data ${ }^{4}$. Amer Indian: American Indian; Hisp: Hispanic; cobi: cobicistat; DTG: dolutegravir; EFV: efavirenz; EVG: elvitegravir; FTC: emtricitabine; RPV: rilpivirine; TAF: tenofovir alafenamide fumarate; TDF: tenofovir disoproxil fumarate. NNRTI-based regimens were switched four weeks before ART interruption due to longer half-lives of NNRTIs. All participants harboured clade B viruses. Viral load <20D: plasma HIV-1 RNA detected but not quantifiable by clinical assays. d0: day 0; dx: diagnosis; Scr: screening. (b) Levels of plasma HIV-1 RNA (black; left y axis) and serum concentration of 3BNC117 (red) and 10-1074 (blue, right y axis) in the 9 participants enrolled in the bNAb+ATI trial ${ }^{4}$. 
a

\begin{tabular}{|c|c|c|c|c|c|c|c|c|c|c|c|c|}
\hline \multirow{2}{*}{ ID } & \multirow{2}{*}{ Age } & \multirow{2}{*}{ Gender } & \multirow{2}{*}{ Race } & \multicolumn{2}{|c|}{ Years since } & \multirow{2}{*}{$\begin{array}{c}\text { Years on } \\
\text { continuous } \\
\text { ART }\end{array}$} & \multirow{2}{*}{ ART regimen } & \multirow{2}{*}{$\begin{array}{c}\text { Reported } \\
\text { CD4 } \\
\text { nadir }\end{array}$} & \multicolumn{2}{|c|}{ CD4 count } & \multicolumn{2}{|c|}{$\begin{array}{c}\text { HIV-1 RNA } \\
(\mathrm{cp} / \mathrm{ml})\end{array}$} \\
\hline & & & & $\begin{array}{c}\text { HIV-1 } \\
\text { dx }\end{array}$ & $\begin{array}{l}\text { first } \\
\text { ART }\end{array}$ & & & & week 0 & week 12 & week 0 & week 12 \\
\hline $1 \mathrm{~A} 17$ & 58 & $\mathrm{~F}$ & Black & 20 & 13 & 13 & EVG/cobi/TAF/FTC & 1,000 & 1,370 & 1,163 & $<20$ & $<20$ \\
\hline $1 \mathrm{~A} 33$ & 50 & $\mathrm{M}$ & Black & 4 & 4 & 4 & EFV/TDF/FTC & 100 & 467 & 429 & $<20 \mathrm{D}$ & $<20$ \\
\hline $1 \mathrm{~B} 50$ & 48 & $\overline{\mathrm{M}}$ & Black & 16 & 16 & 16 & RPV/TAF/FTC & 400 & 461 & 483 & $<20$ & $<20 \mathrm{D}$ \\
\hline $1 \mathrm{~B} 26$ & 54 & $\mathrm{M}$ & Black & 25 & 16 & 16 & RAL/SQV/rit/TDF & 5 & 707 & 905 & $<20$ & $<20$ \\
\hline B531 & 25 & $\mathrm{M}$ & Black & 3 & 3 & 3 & EVG/cobi/TDF/FTC & 350 & 750 & 759 & $<20 \mathrm{D}$ & $<20$ \\
\hline B533 & 59 & $\mathrm{M}$ & Black & 28 & 28 & 21 & RAL/DRV/cobiTDF/FTC & 50 & 715 & n.d. & $<<20$ & $<20$ \\
\hline B535 & 51 & M & $\begin{array}{c}\text { Hispanic/ } \\
\text { multiple }\end{array}$ & 14 & 14 & 14 & EFV/TDF/FTC & 100 & 642 & n.d. & $<20$ & $<20$ \\
\hline B536 & 34 & $\mathrm{M}$ & White & 8 & 4 & 4 & EVG/cobi/TAF/FTC & 750 & 1,022 & n.d. & $<20$ & $<20$ \\
\hline B539 & 29 & $\mathrm{M}$ & White & 4 & 4 & 4 & EVG/cobi/TAF/FTC & 500 & 741 & n.d. & $<20$ & $<20$ \\
\hline B544 & 36 & $\bar{M}$ & White & 12 & 11 & 11 & $\mathrm{DTG} / \mathrm{ABC} / 3 \mathrm{TC}$ & 350 & 504 & n.d. & $<20$ & $<20$ \\
\hline B545 & 30 & $\mathrm{M}$ & Black & 4 & 4 & 4 & DTG/ABC/3TC & 238 & 559 & n.d. & $<20$ & $<20$ \\
\hline B550 & 48 & $\mathrm{~F}$ & Black & 11 & 11 & 11 & RPV/TAF/FTC & 600 & 868 & n.d. & 40 & $<20$ \\
\hline B554 & 49 & $\mathrm{M}$ & Black & 24 & 24 & 4 & DGV/TDF/FTC & 560 & 834 & n.d. & $<20$ & $<20$ \\
\hline
\end{tabular}

b

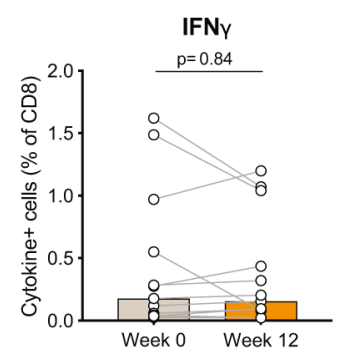

IFNY

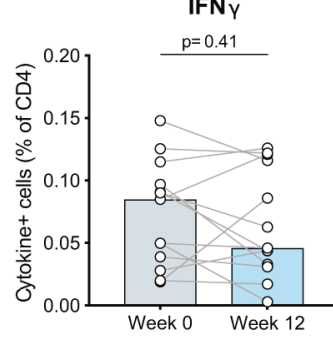

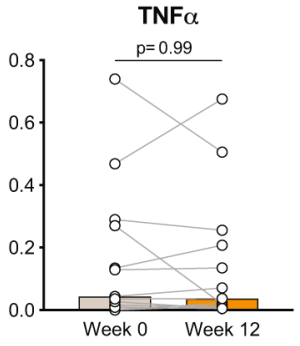

TNF $\alpha$

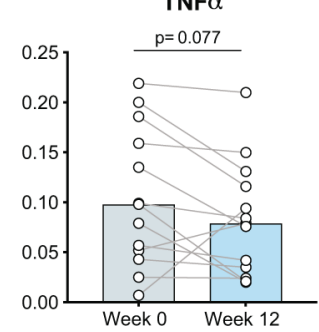

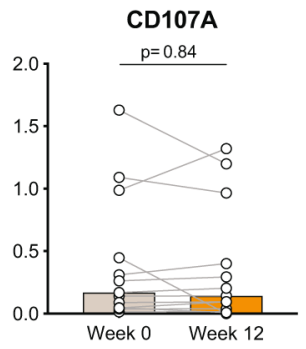

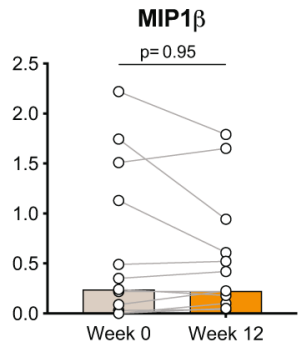

IL-2
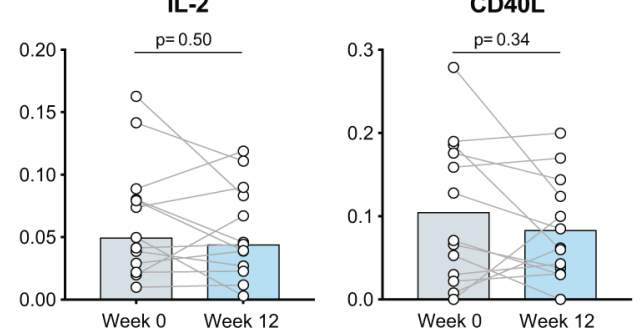

Total cytokine+

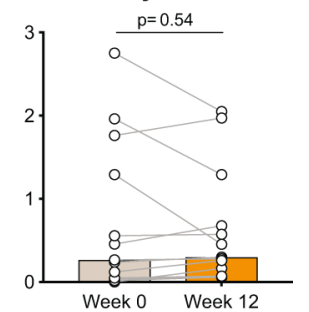

Total cytokine+ $p=0.24$

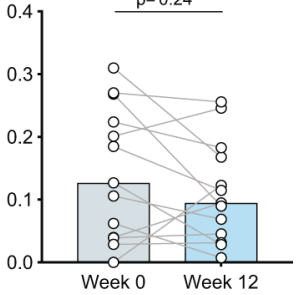

Extended Data Fig. 2 | Frequency of Gag-specific CD4 ${ }^{+}$and $\mathrm{CD}^{+}$unchanged in ART-treated individuals over time. T cell cytokine coexpression after $6 \mathrm{~h}$ HIV-1 Gag peptide pool stimulation was evaluated by intracellular cytokine staining (ICS) in individuals on continuous ART. (a) Demographics and clinical data of ART-treated individuals. 3TC: lamivudine; ABC: abacavir; cobi: cobicistat; DRV: darunavir; DTG: dolutegravir; EFV: efavirenz; EVG: elvitegravir; FTC: emtricitabine; RAL: raltegravir; rit: ritonavir; RPV: rilpivirine; SQV: saquinavir; TAF: tenofovir alafenamide fumarate; TDF: tenofovir disoproxil fumarate. Viral load <20D: plasma HIV-1 RNA detected but not quantifiable by clinical assays. n.d.: not determined. (b) Cytokine analysis of CD8 ${ }^{+}$and CD4+ after HIV-1 Gag peptide pool stimulation at week 0 and 12. Symbols represent biologically independent samples from $n=13$ individuals on continuous ART. Lines connect data from the same donor. Bars show median values. P values were calculated by paired two-tailed Wilcoxon test. 


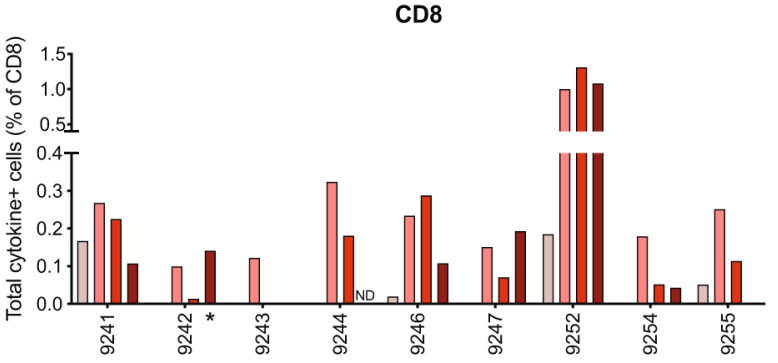

b

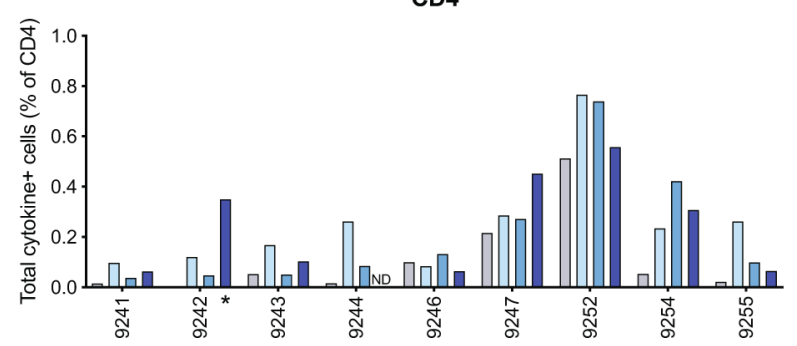

$\square$ Week -2

$\square$ Week 6/7

$\square$ Week 12

$\square$ Week 18

Extended Data Fig. 3 | Individual Gag-specific T cell responses measured by ICS. (ab) Net frequency of total cytokine ${ }^{+}$CD $8^{+}(\mathbf{a})$ or $C D 4^{+}$cells $(\mathbf{b})$ after Gag stimulation for each individual study participant. Total cytokine ${ }^{+}$cells include cells that express at least one cytokine/effector function upon Gag stimulation (CD107A, IFN $\gamma$, MIP1 $\beta$ and/or TNF $\alpha$ for CD8 ${ }^{+}$; CD4OL, IFN $\gamma$, IL-2 and/or TNF $\alpha$ for CD4 $4^{+}$). Net value was calculated by subtracting frequency of total cytokine ${ }^{+}$cells detected in a DMSO control. ND: Week 18 sample was not available for individual 9244 . ${ }^{\star} 9242$ week 18 on ART after viral rebound at week 15 . 
$a$
0
00
0
1
00
00
$\sum_{0}^{0}$
0

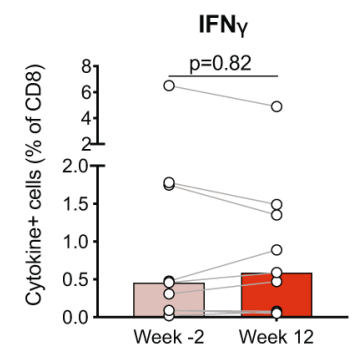

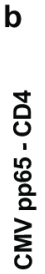

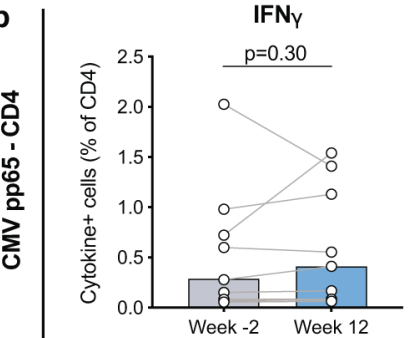

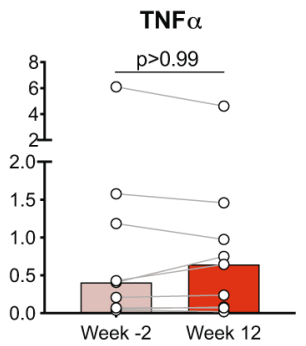
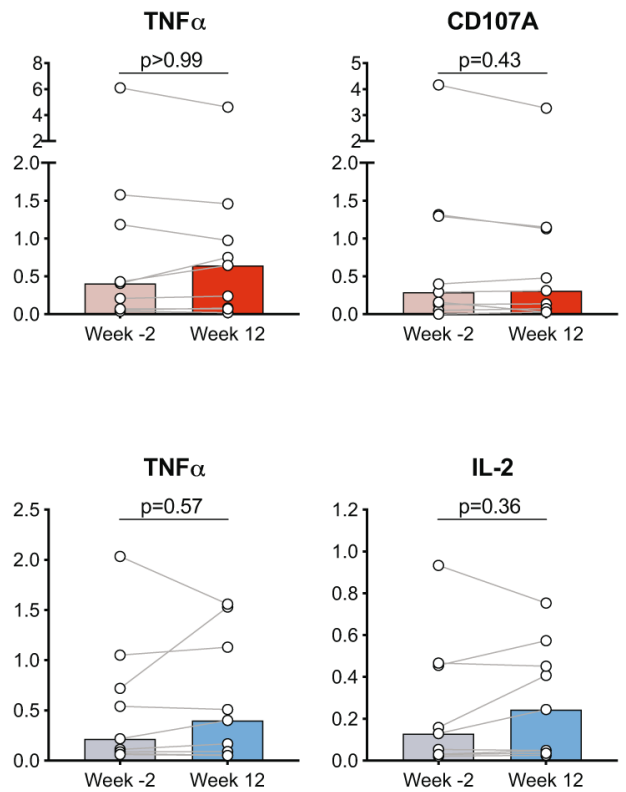

IL-2

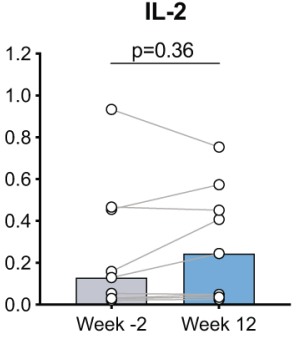

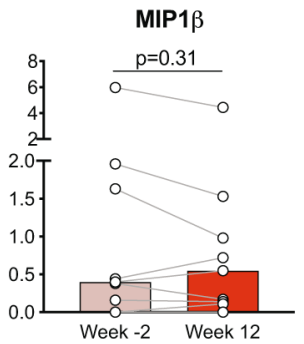
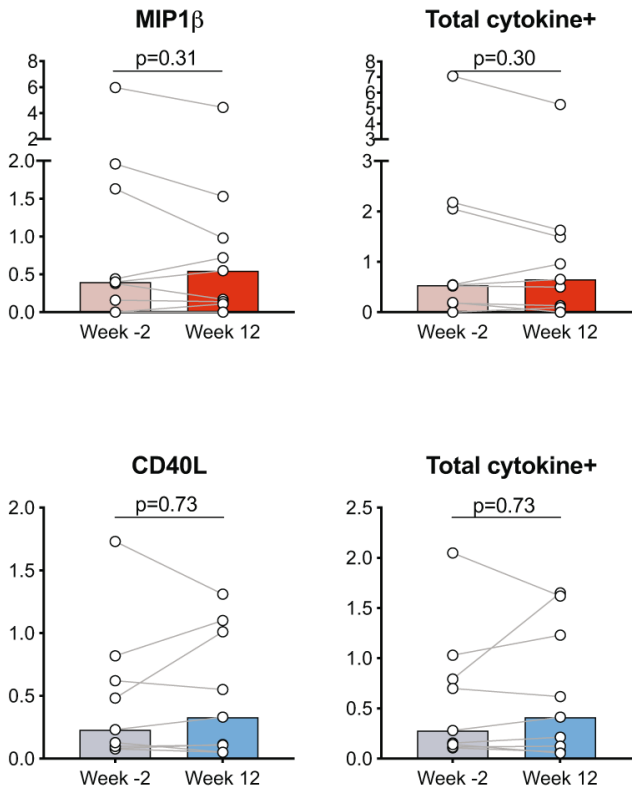

Total cytokine+

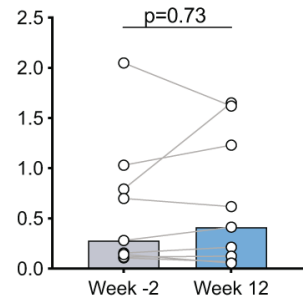

Extended Data Fig. 4 | Unchanged frequency of CMV-specific effector T cells detected by intracellular cytokine staining. PBMCs were stimulated with CMV pp65 peptide pools for $6 \mathrm{~h}$ and cytokine production was evaluated by ICS in bNAb+ATI individuals at week -2 and week 12 . (ab) Cytokine analysis of $\mathrm{CD}^{+}(\mathbf{a})$ or CD4+ $\mathrm{T}$ cells (b) at week -2 and week 12 after CMV pp65 stimulation. Net frequency of stimulated condition was calculated by subtracting frequency detected in a DMSO control. Symbols represent biologically independent samples from $n=9 b N A b+A T I$ individuals. Lines connect data from the same donor. Bars show median values. P values are indicated in graphs and were calculated by paired two-tailed Wilcoxon test. 
a

\begin{tabular}{|c|c|c|c|c|c|c|c|c|c|c|c|c|c|c|c|}
\hline \multirow[b]{2}{*}{ ID } & \multirow[b]{2}{*}{ Age } & \multirow[b]{2}{*}{ Gender } & \multirow[b]{2}{*}{ Race } & \multicolumn{2}{|c|}{ Years since } & \multirow{2}{*}{$\begin{array}{c}\text { Uninterr. } \\
\text { ART } \\
\text { before ATI } \\
\text { (yrs) } \\
\end{array}$} & \multirow[b]{2}{*}{$\begin{array}{c}\text { ART at } \\
\text { screening }\end{array}$} & \multirow[b]{2}{*}{$\begin{array}{c}\text { Switched } \\
\text { ART }\end{array}$} & \multirow{2}{*}{$\begin{array}{c}\text { Reported } \\
\text { CD4 } \\
\text { nadir } \\
\end{array}$} & \multirow[b]{2}{*}{$\begin{array}{l}\text { HLA } \\
\text { alleles }\end{array}$} & \multirow{2}{*}{$\begin{array}{l}\text { CD4 } \\
\text { count } \\
\text { (d0) }\end{array}$} & \multicolumn{3}{|c|}{ HIV-1 RNA (cp/ml) } & \multirow{2}{*}{$\begin{array}{l}\text { Weeks to } \\
\text { viral } \\
\text { rebound }\end{array}$} \\
\hline & & & & $\begin{array}{c}\text { HIV-1 } \\
\mathrm{dx}\end{array}$ & $\begin{array}{l}\text { first } \\
\text { ART }\end{array}$ & & & & & & & Ser & $\begin{array}{c}\text { Week } \\
-2\end{array}$ & d0 & \\
\hline 9245 & 22 & M & White/Hisp & 5 & 5 & 5 & $\begin{array}{l}\text { EVG/cobi/ } \\
\text { TAF/FTC }\end{array}$ & - & 360 & $\begin{array}{c}\mathrm{A} 2,24 ; \\
\text { B15,15; } \\
\text { C4,8 }\end{array}$ & 736 & $<20$ & $<20$ & $<20$ & 5 \\
\hline 9251 & 40 & M & Black & 6 & 2 & 2 & $\begin{array}{l}\text { EVG/cobi/ } \\
\text { TDF/FTC }\end{array}$ & - & 1,000 & $\begin{array}{c}\text { A2,34; } \\
\text { B45,53; } \\
\text { C4,16 }\end{array}$ & 672 & $<20$ & $<20$ & $<20$ & 7 \\
\hline
\end{tabular}

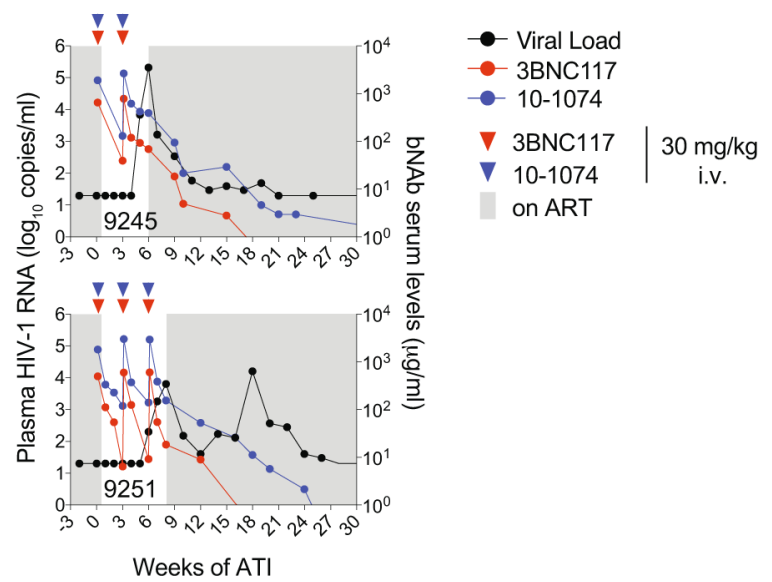

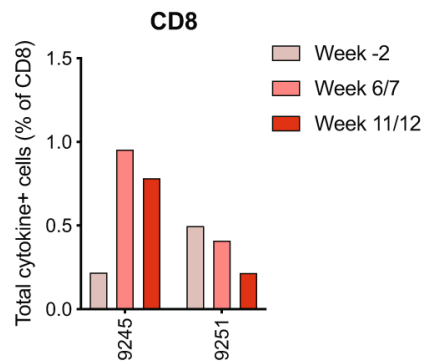

CD4

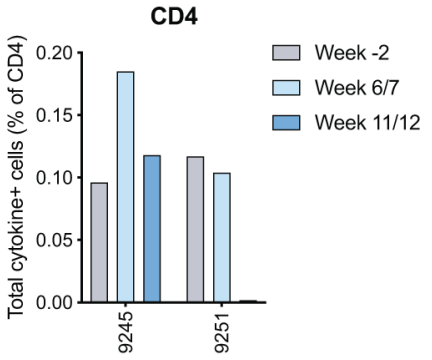

Extended Data Fig. 5 | HIV-1 Gag-specific T cell responses in early rebounders with bNAb-resistant reservoir. (a) Study participant demographics and baseline clinical data ${ }^{4}$. Hisp: Hispanic; cobi: cobicistat; EVG: elvitegravir; FTC: emtricitabine; TAF: tenofovir alafenamide fumarate; TDF: tenofovir disoproxil fumarate. All participants harboured clade B viruses. d0: day 0; dx: diagnosis; Scr: screening. (b) Levels of plasma HIV-1 RNA (black; left y axis) and serum concentration of 3BNC117 (red) and 10-1074 (blue, right y axis) in the 2 participants enrolled in the bNAb+ATI trial with early rebound due to bNAbresistant reservoir ${ }^{4}$. (c) Net frequency of total cytokine ${ }^{+}$CD8 ${ }^{+}$or CD4 ${ }^{+}$T cells after HIV-1 Gag stimulation in both individuals at weeks $-2,7$ and 11 (9245), or weeks $-2,6$ and 12 (9251). 
a

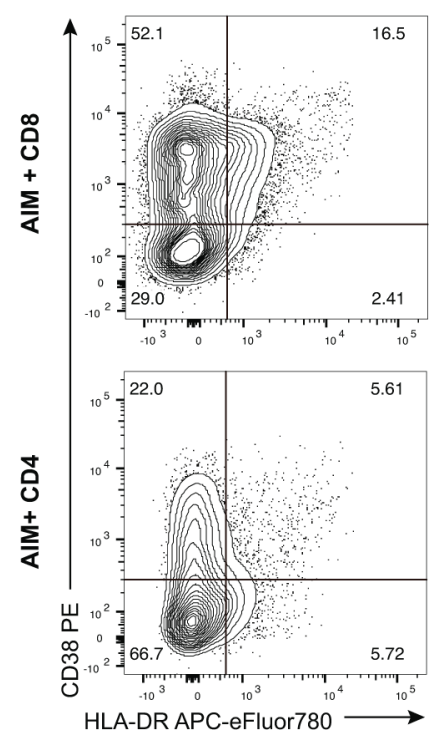

PD-1

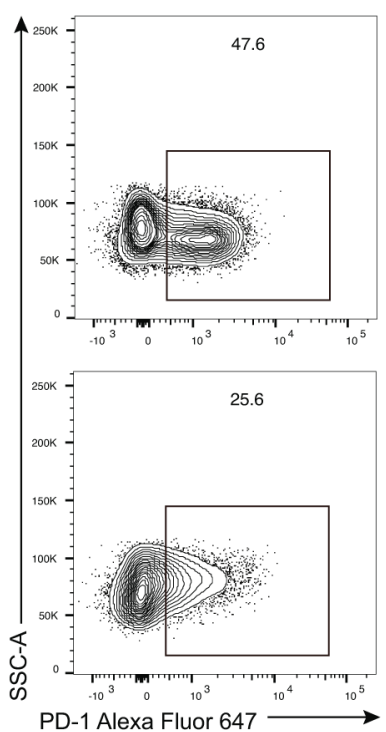

b
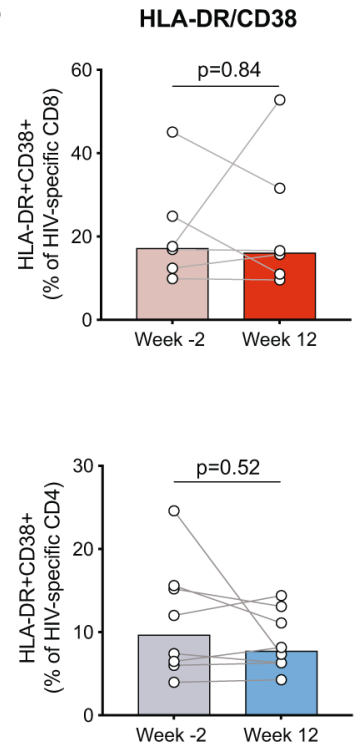

PD-1
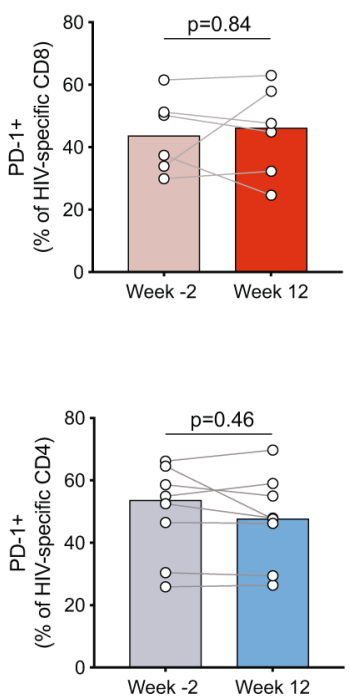

Extended Data Fig. 6 | No change in HLA-DR/CD38 and PD-1 expression of HIV-1-specific T cell responses. HIV-1-specific T cell responses identified by PD-L1/CD69/4-1BB AIM assay were analyzed for surface expression of HLA-DR/CD38 and PD-1. (a) Representative plot showing expression of HLA-DR/ CD38 and PD-1 on AIM+ HIV-1-specific CD8 (upper graphs) and CD4+ $4^{+}$cells (lower graphs). Flow panels are representative of $n=6\left(C D 8^{+}\right)$or $n=8$ $\left(\mathrm{CD} 4^{+}\right.$) biologically independent bNAb+ATI individuals. (b) Frequency of HLA-DR+CD38+ or PD-1+ of HIV-1-specific CD8 ${ }^{+}$and $\mathrm{CD} 4^{+} \mathrm{T}$ cell responses at week -2 or week 12 . Symbols represent biologically independent samples from $n=6\left(C D 8^{+}\right)$and $n=8\left(C D 4^{+}\right)$bNAb+ATI individuals. Only samples with AIM-responses that are at least 2-fold over DMSO-stimulated control condition were analyzed for phenotype to limit the contribution of background events. Lines connect data from the same donor. Bars show median values. P values are indicated in graphs and were calculated by paired two-tailed Wilcoxon test. 
a

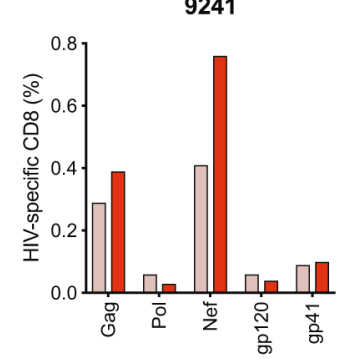

9246

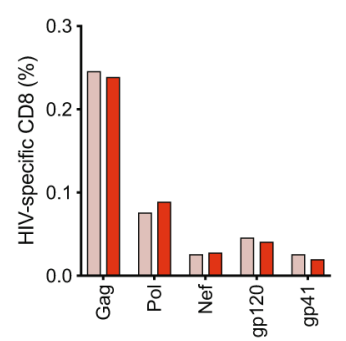

b

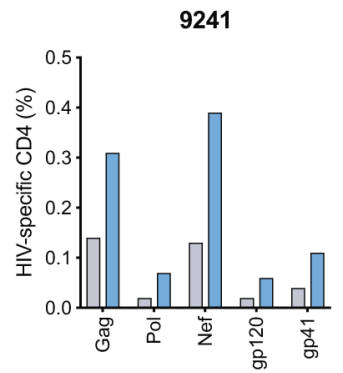

9246

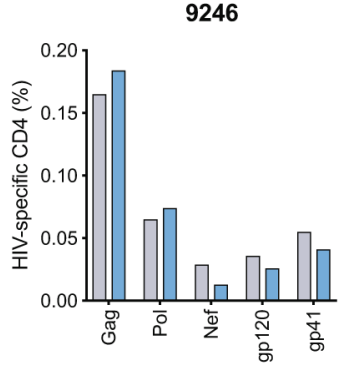

9242

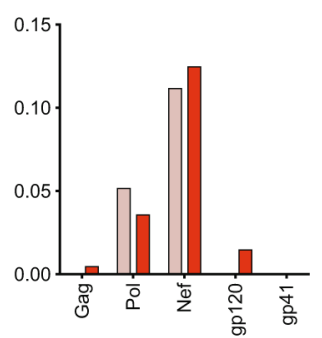

9247

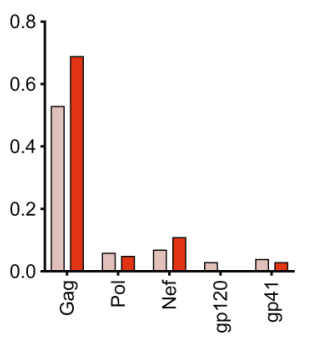

9242

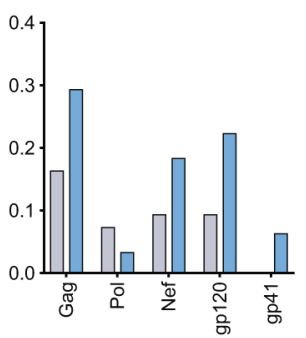

9247

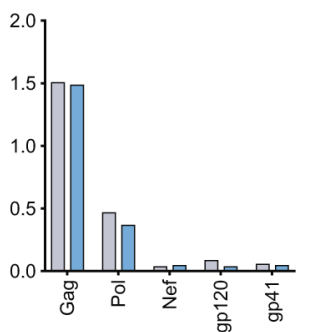

9243

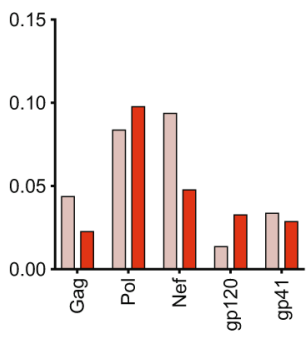

9252

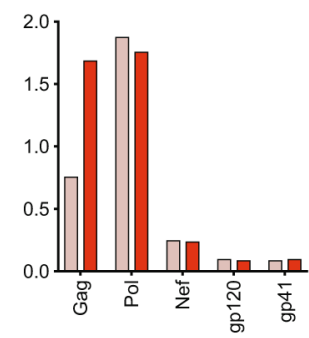

9243

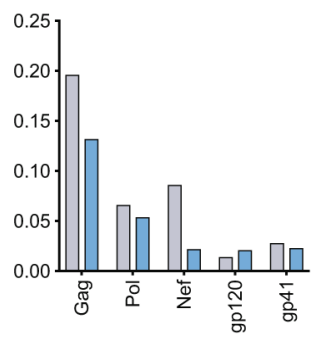

9252

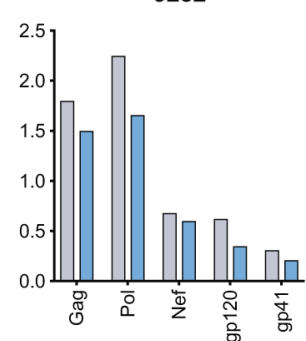

9244

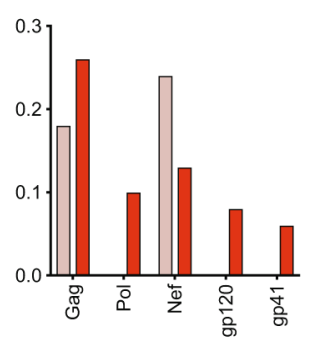

* 9254

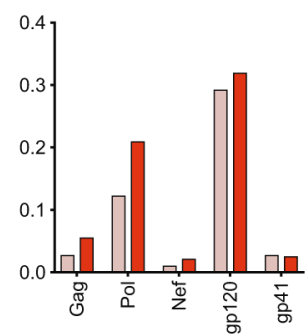

9244

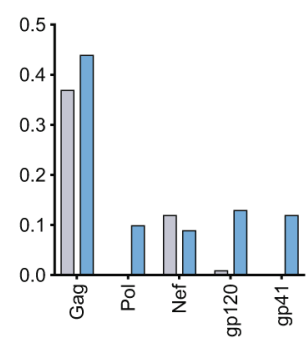

* 9254

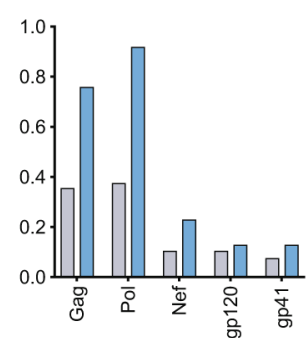

$\square$ Week -2

$\square$ Week 12

C

CD8

CD4

CD4 + CD8
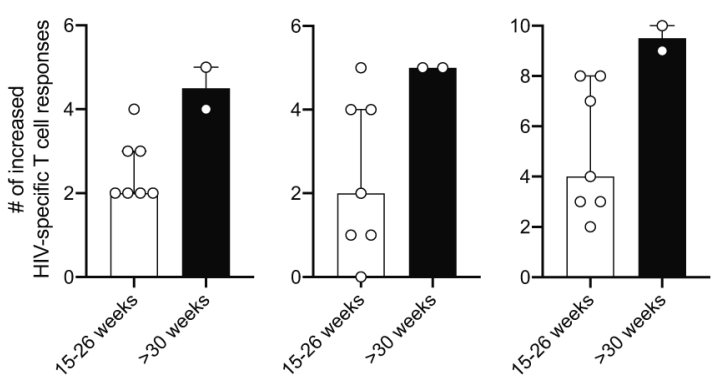

Extended Data Fig. 7 | Dynamics of T cell responses to multiple HIV-1 antigens in bNAb+ATI individuals. (ab) Frequency of CD8+ (a) and CD4+ T cells (b) specific to HIV-1 Pol, Nef, gp120 or gp41 were evaluated by CD69/PD-L1/4-1BB AIM assay at weeks -2 and 12 . Individuals with viral suppression $>30$ weeks $(9254,9255)$ are marked with an asterisk $\left(^{*}\right)$. (c) Number of increased HIV-specific CD4 ${ }^{+}$and CD8 ${ }^{+} \mathrm{T}_{\text {cell }}$ responses in $n=7$ biologically independent individuals with 15-26 weeks of viral control after ATI (15-26 weeks: 9241, 9242, 9243, 9244, 9246, 9247, 9252) versus n=2 biologically independent individuals with viral control beyond 30 weeks after ATI (>30 weeks: 9254 and 9255). Number of increased HIV-specific T cell responses was calculated as the sum of single HIV antigens (Gag, Pol, Nef, gp120, gp41) for which we observed an increase at week 12 versus week -2. Bars represent median values with IQR. 


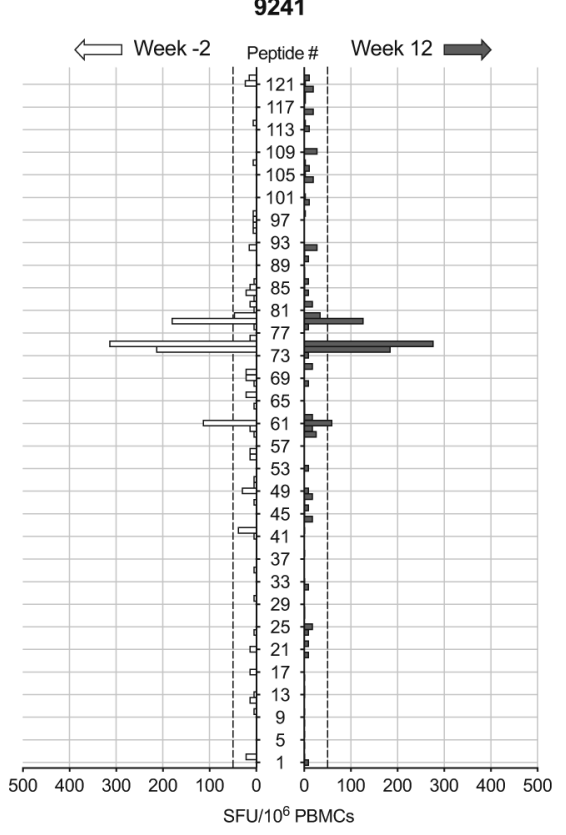

d

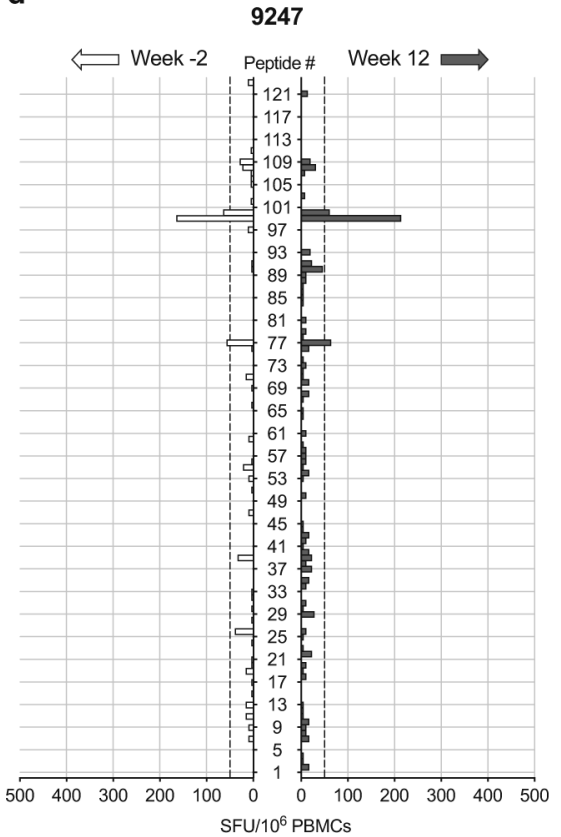

b

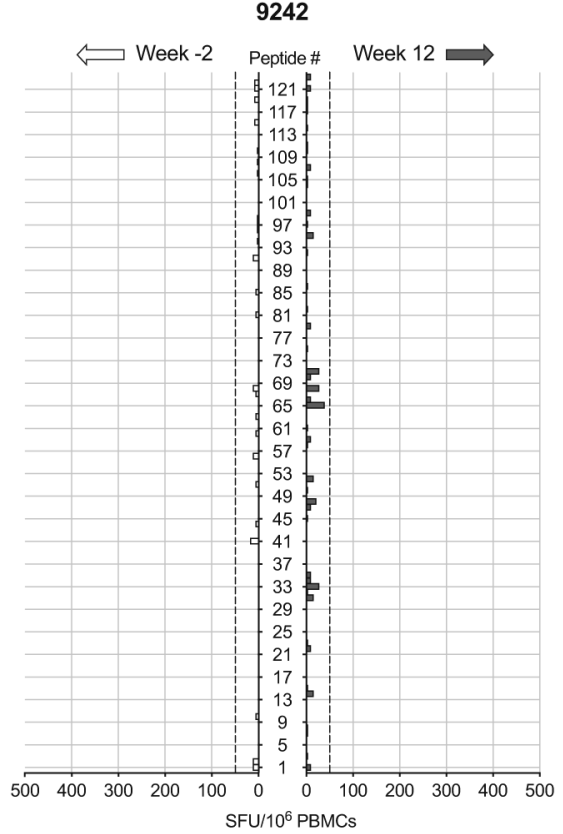

e

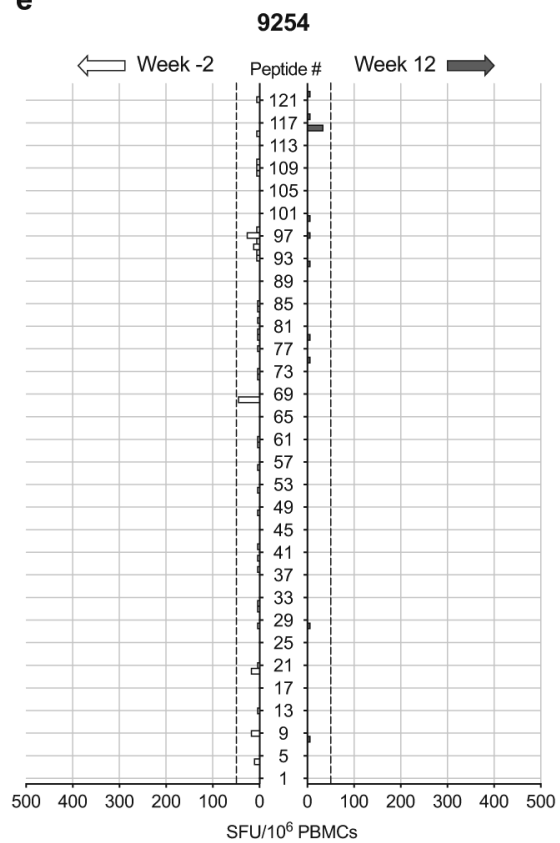

c

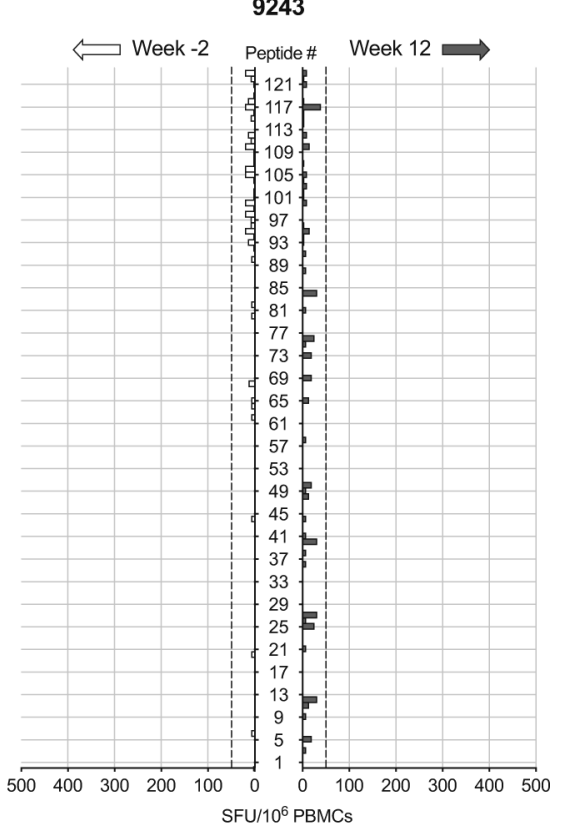

f

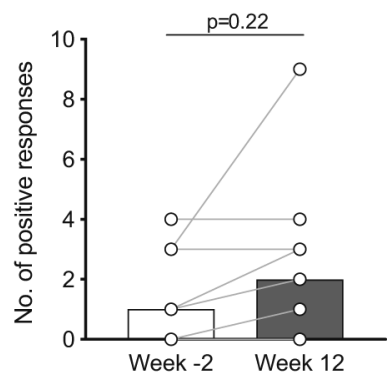

Extended Data Fig. 8 | PBMC IFN $\gamma$ ELISpot responses were undetectable/not changed in 5 individuals. PBMCs were evaluated for IFN $\gamma$ ELISpot responses to $123 \mathrm{HIV}-1$ Gag peptides spanning the entire Gag protein. Spot forming units (SFU) were calculated as number of spots in test wells subtracted by mean number of spots in media control wells and normalized to SFU $/ 10^{6} \mathrm{PBMCs}$. A response was considered positive if greater than $50 \mathrm{SFU} / 10^{6} \mathrm{PBMCs}$ (=limit of detection, LOD, dashed line). (a-e) Graph representing IFN $\gamma$ ELISpot responses for individuals with either undetectable (9242 (b), 9243 (c), 9254 (e)) or unchanged response ( 9241 (a), 9247 (d)) at week -2 (left axis, white bars) and week 12 (right axis, gray bars). (f) Number of responses above LOD for $n=9$ biologically independent bNAb+ATI individuals at week -2 and week 12 . Lines connect data from the same donors, bars represent median values. $P$ value was calculated by paired two-tailed Wilcoxon test. 
a

No infection

CD4

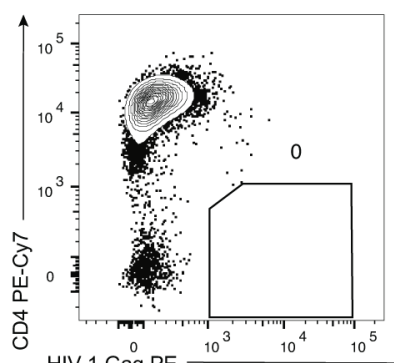

HIV-1 $1_{\text {BaL }}$ infection

CD4 + CD8 week -2

CD4 + CD8 week 12

CD4

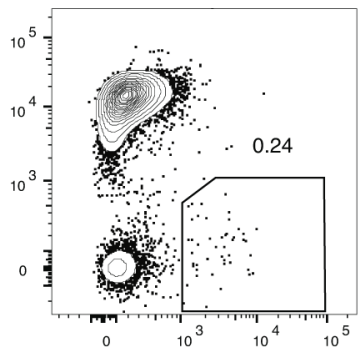

b
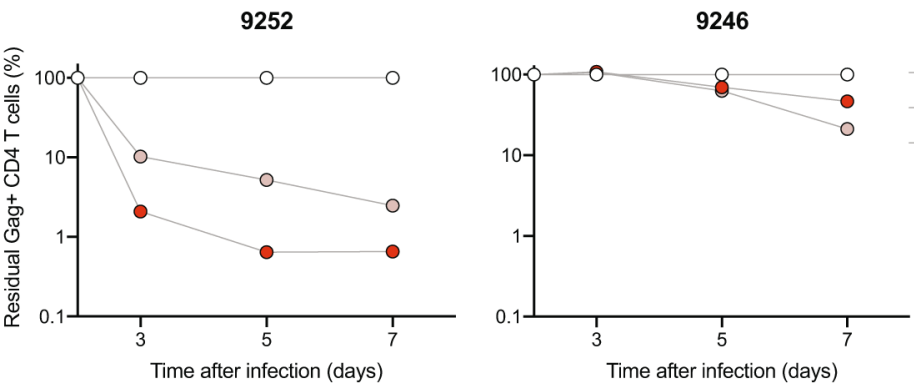

C

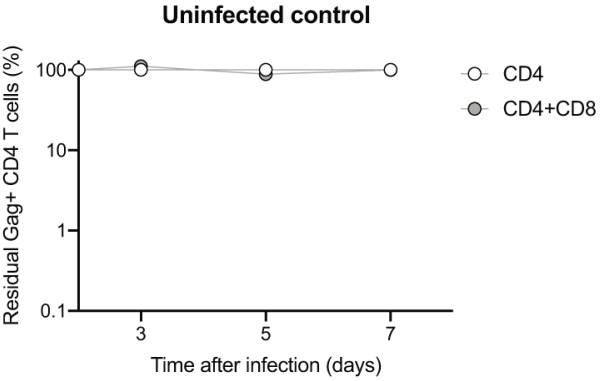

Extended Data Fig. 9 | In vitro HIV-1 inhibition assay for individuals 9252 and $\mathbf{9 2 4 6 .}$ PHA-activated CD4+ ${ }^{+}$cells were infected in vitro with HIV- BaL' cultured alone or in presence with autologous CD8 ${ }^{+}$T cells for 3, 5 and 7 days, and analyzed for infection using flow cytometry. (a) Example plot showing the frequency of infected CD4+ T cells (HIV-1 Gag+ cells with down-regulated surface CD4) for bNAb+ATI individual 9252 . Flow panels are representative of $n=3$ technical replicates. (b) Fraction of residual HIV-1 Gag+CD4- T cells after 3, 5 or 7 days of co-culture with CD8 ${ }^{+}$T cells obtained at week -2 or week 12 for $n=2$ biologically independent individuals (9252 and 9246) normalized to infected CD4+ T cells cultured without CD8+ T cells. (c) Fraction of residual HIV-1 Gag ${ }^{+}$CD4- T cells after 3, 5 or 7 days of co-culture with autologous CD8 ${ }^{+}$T cells for one HIV-1-uninfected control individual. Each condition was done in technical duplicates or triplicates depending on cell availability and mean values are shown. 
9241

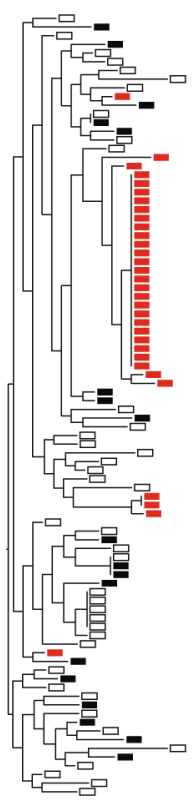

$\overline{0.002}$
9242*

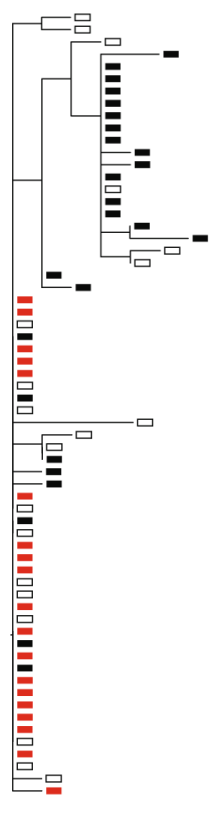

$\overline{0.002}$
9243*

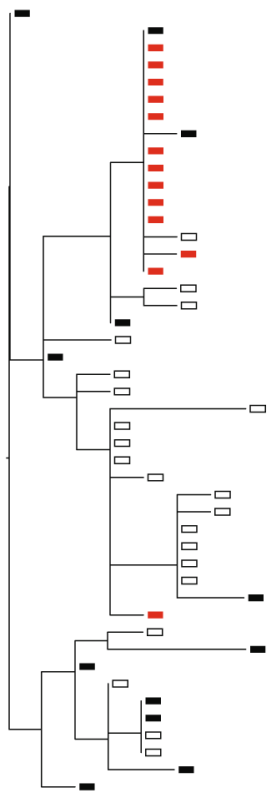

$\overline{0.002}$
9244

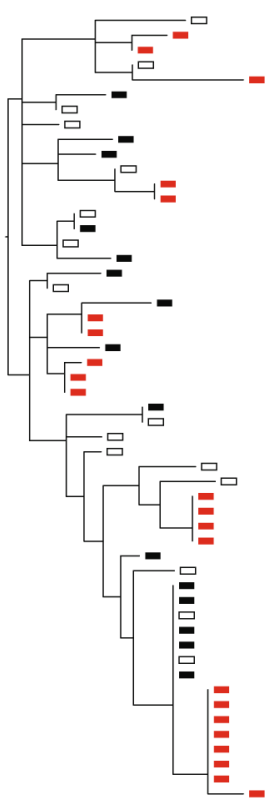

$\overline{0.008}$
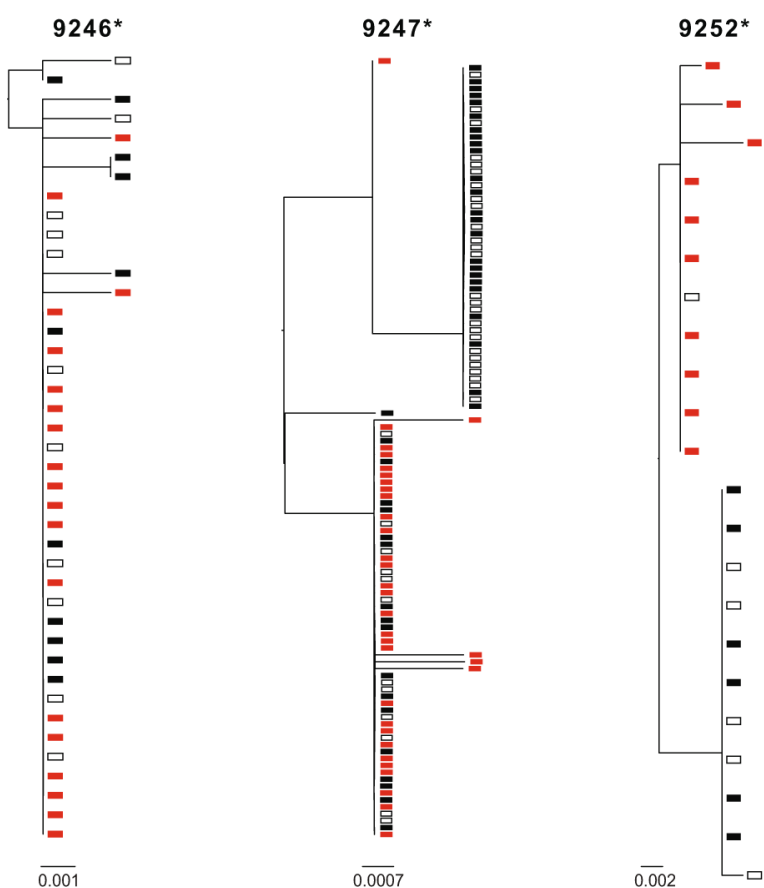

* Identical match

$\square$ Week -2

- Week 12

- Rebound

Extended Data Fig. 10 | Comparison of the circulating latent reservoir and rebound viruses. Maximum likelihood phylogenetic trees of full-length gag sequences isolated from CD4 ${ }^{+}$T cell genomic near-full length (NFL) HIV-1 sequencing and rebound plasma SGA from participants 9241, 9242, 9243, 9244, 9246, 9247 and 9252. Open and closed black rectangles indicate NFL-derived viruses from pre-infusion (week -2) and week 12, respectively. Viruses obtained at the time of rebound are indicated by red rectangles (plasma SGA). Asterisks indicate individuals where there is at least one identical match between a gag sequence from the latent reservoir and the rebound viruses. 


\section{Reporting Summary}

Nature Research wishes to improve the reproducibility of the work that we publish. This form provides structure for consistency and transparency in reporting. For further information on Nature Research policies, see Authors \& Referees and the Editorial Policy Checklist.

\section{Statistics}

For all statistical analyses, confirm that the following items are present in the figure legend, table legend, main text, or Methods section.

n/a Confirmed

$\bigotimes$ The exact sample size $(n)$ for each experimental group/condition, given as a discrete number and unit of measurement

$\square$ A statement on whether measurements were taken from distinct samples or whether the same sample was measured repeatedly

$\square$ The statistical test(s) used AND whether they are one- or two-sided

Only common tests should be described solely by name; describe more complex techniques in the Methods section.

$\triangle \square$ A description of all covariates tested

\ $\square$ A description of any assumptions or corrections, such as tests of normality and adjustment for multiple comparisons

A full description of the statistical parameters including central tendency (e.g. means) or other basic estimates (e.g. regression coefficient)

AND variation (e.g. standard deviation) or associated estimates of uncertainty (e.g. confidence intervals)

For null hypothesis testing, the test statistic (e.g. $F, t, r$ ) with confidence intervals, effect sizes, degrees of freedom and $P$ value noted Give $P$ values as exact values whenever suitable.

Х $\square$ For Bayesian analysis, information on the choice of priors and Markov chain Monte Carlo settings

Х $\square$ For hierarchical and complex designs, identification of the appropriate level for tests and full reporting of outcomes

$\square \bigotimes$ Estimates of effect sizes (e.g. Cohen's d, Pearson's $r$ ), indicating how they were calculated

Our web collection on statistics for biologists contains articles on many of the points above.

\section{Software and code}

Policy information about availability of computer code

Data collection

DIVA 8.0.1 (cytometer), Immunospot 5.0 (ELISpot), MiSeq Control Software 2.6 2.1 (sequencing)

Data analysis

Flow cytometry data were analyzed with Flowjo v10 (Treestar) and statistical analyses were performed with Prism v8 for Mac (Graphpad Software Inc). Amino acid alignments of intact gag sequences were obtained by using ClustalW v.2.1 under the BLOSUM cost matrix. Sequences with premature stop codons were excluded from all analyses. Maximum likelihood phylogenetic trees were then generated from these alignments using RAXML v.8.2.9 under the GTRGAMMA model with 1,000 bootstraps. To analyze changes between reservoir and rebound viruses, gag sequences were aligned at the amino acid level to a HXB2 reference using ClustalW v.2.1.

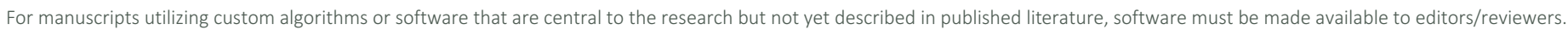
We strongly encourage code deposition in a community repository (e.g. GitHub). See the Nature Research guidelines for submitting code \& software for further information.

Data

Policy information about availability of data

All manuscripts must include a data availability statement. This statement should provide the following information, where applicable:

- Accession codes, unique identifiers, or web links for publicly available datasets

- A list of figures that have associated raw data

- A description of any restrictions on data availability

Sequences from all isolated viruses are available in GenBank, accession numbers MN750027 - MN750174. Additional datasets that support the findings of this study are available from the corresponding authors on reasonable request. 
Please select the one below that is the best fit for your research. If you are not sure, read the appropriate sections before making your selection.

$\bigotimes$ Life sciences $\quad \square$ Behavioural \& social sciences $\quad \square$ Ecological, evolutionary \& environmental sciences

For a reference copy of the document with all sections, see nature.com/documents/nr-reporting-summary-flat.pdf

\section{Life sciences study design}

All studies must disclose on these points even when the disclosure is negative.

Sample size No sample size calculation was performed.

Results obtained from the bNAb+ATI clinical trial (NCT02825797) have been previously published in Mendoza et al., Nature 561, 479-484

(2018). Nine of the 15 study participants who fulfilled the study eligibility criteria harbored latent reservoir that was sensitive to both bNAbs

(10-1074 and 3BNC117) and maintained viral suppression for 15 to $>30$ weeks after ART discontinuation.

We analyzed all available study participants $(n=9)$ with prolonged viral suppression for this manuscript.

In addition, two study participants who harbored latent reservoir that was resistant to one of the two bNAbs and who rebounded early after ATI (week 5 or 7) were analyzed (Extended Data Figure 5).

The number of individuals included in the historical comparison group of people on continuous ART $(n=13)$ was chosen to approximately match the number of participants enrolled into the Phase Ib trial.

Data exclusions No participant fulfilling the criteria mentioned above was excluded from the analyses.

Replication Samples analyzed in this study were obtained from participants of a clinical trial (bNAb+ATI) or an observational study (ART) and samples were analyzed on individual study participants. Experiments did not include replicates as all participants and data points are unique.

Randomization The bNAb+ATI clinical trial was single arm.

Blinding The bNAb+ATI clinical trial was open label.

\section{Reporting for specific materials, systems and methods}

We require information from authors about some types of materials, experimental systems and methods used in many studies. Here, indicate whether each material, system or method listed is relevant to your study. If you are not sure if a list item applies to your research, read the appropriate section before selecting a response.

\begin{tabular}{|c|c|c|c|}
\hline \multicolumn{2}{|c|}{ Materials \& experimental systems } & \multicolumn{2}{|c|}{ Methods } \\
\hline$n / a$ & Involved in the study & $\mathrm{n} / \mathrm{a}$ & Involved in the study \\
\hline$\square$ & $\bigotimes$ Antibodies & Х & $\square$ ChIP-seq \\
\hline$\bigotimes$ & $\square$ Eukaryotic cell lines & $\square$ & 叉 Flow cytometry \\
\hline$\bigotimes$ & Palaeontology & Х & $\square$ MRI-based neuroimaging \\
\hline 邓 & $\square$ Animals and other organisms & & \\
\hline$\square$ & \ Human research participants & & \\
\hline$\square$ & $\bigotimes$ Clinical data & & \\
\hline
\end{tabular}

\section{Antibodies}

Antibodies used

3BNC117 and 10-1074 are investigational anti-HIV-1 neutralizing antibodies manufactured for clinical use. They are being investigated under US FDA INDs 118225 and 123713.

All antibodies used for flow cytometry are listed in supplementary tables 1, 2 and 5, which describe the specific panels used.

1. CD3 BUV395, UCHT1, BD Biosciences 563548, lot \#6343984, $3 \mu \mathrm{l} /$ test

2. CD4 BUV496, SK3, BD Biosciences 564651, lot \#9080989, $4 \mu \mathrm{l} /$ test

3. CD8 APC-Fire750 SK1, Biolegend 344745, lot\#B237278, $0.5 \mu \mathrm{l} /$ test

4.CD14 BV510 M5E2, Biolegend 301842, lot\#B250901, 3 Ml/test

5.CD19 BV510, M1B19, Biolegend 302242, lot\#B239285, $3 \mu$ l/test

6. CD40L BV421, TRAP1, BD Biosciences 563886, lot\#6280762, $5 \mu$ l/test

7. CD56 BUV737, NCM16.2, BD Biosciences 564448, lot\#8288818, $2.5 \mu \mathrm{l} /$ test

8. CD69 PerCP-eFluor710, FN50, eBioscience 46-0699-42, lot\#1920361, $4 \mu \mathrm{l} /$ test

9. CD107A BV786, H4A3, BD Biosciences 563869, lot\#8144866, $5 \mu \mathrm{l} /$ test

10. IFNy PE-Cy7, B27, BD Biosciences 557643, lot\#7202642, $4 \mu$ l/test

11. IL-2 PE-Dazzle594, MQ1-17H12, Biolegend 500344, lot\#B245312, $3.5 \mu \mathrm{l} /$ test

12. MIP1ß PE, D21-1351, BD Biosciences 550078, lot\#8176503, $1 \mu$ l/test 
13. TNFa APC, Mab11, BD Biosciences 562084, lot\#7163931, $1.5 \mu \mathrm{l} /$ test

14. CD3 PerCP-efluor710, SK7, eBioscience 46-0036, lot\#1941534, $3 \mu \mathrm{l} /$ test

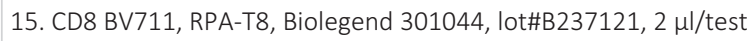

16. CD69 BUV395, FN50, BD Biosciences 564364, lot\#8242749, $5 \mu$ l/test

17. CD137 (4-1BB) PE-Cy7, 4B4-1, Biolegend 309818, lot\#B258325, 5 l/test

18. PD-L1 BV421, 29E2A3, Biolegend 329714, lot\#B258010, 5 l/test

19. HLA-DR APC-eFluor780, LN3, eBioscience 47-9956, lot\#4312829, $2.5 \mu l$ /test

20. CD38 PE, HB7, BD Biosciences 342371, lot\# 8234511, $10 \mu \mathrm{l} /$ test

21. PD-1 Alexa Fluor 647, EH12.2H7, Biolegend 329910, lot\# B241533, $2.5 \mu l /$ test

22. CD4 PE-Cy7, RPA-T4, BD Biosciences 560649, lot\#9086795, $4 \mu \mathrm{l} /$ test

23. CD14 BUV737, M5E2, BD Biosciences 564444, lot\# 7150893, $2 \mu l$ test

24. CD19 BUV737, SJ25C1, BD Biosciences 564303, lot\#5100759, $3 \mu$ l/test

25. HIV-1 Gag PE, KC57, Beckman Coulter 6604667, lot\#7433072, 1 l/test

Validation

3BNC117 and 10-1074 that were administered to the participants were manufactured by Celldex Therapeutics under Good Manufacturing Practice and have been fully characterized in terms of biophysical properties and potency (INDs 118225 and 123713). Both drug products are under long term stability monitoring.

3BNC117 and 10-1074 are investigational anti-HIV-1 neutralizing antibodies manufactured for clinical use. They are being investigated under US FDA INDs 118225 and 123713.

All antibodies used for flow cytometry were commercially available. Clones and companies are listed in the supplementary tables 1,2 and 5.

1. CD3 BUV395, reactivity: human (QC testing, BD Biosciences), application: flow cytometry (routinely tested, BD Biosciences)

2. CD4 BUV496, reactivity: human (QC testing, BD Biosciences), application: flow cytometry (routinely tested, BD Biosciences)

3. CD8 APC-Fire750, reactivity: human (Biolegend), application: flow cytometry (quality tested, Biolegend)

4.CD14 BV510, reactivity: human (Biolegend), application: flow cytometry (quality tested, Biolegend)

5.CD19 BV510, reactivity: human (Biolegend), application: flow cytometry (quality tested, Biolegend)

6. CD40L BV421, reactivity: human (QC testing, BD Biosciences), application: flow cytometry (routinely tested, BD Biosciences)

7. CD56 BUV737, reactivity: human (QC testing, BD Biosciences), application: flow cytometry (routinely tested, BD Biosciences)

8. CD69 PerCP-eFluor710, reactivity: human (ThermoFisher), tested applications: flow cytometry (Thermofisher)

9. CD107A BV786, reactivity: human (QC testing, BD Biosciences), application: flow cytometry (routinely tested, BD Biosciences)

10. IFNY PE-Cy7, reactivity: human (QC testing, BD Biosciences), application: flow cytometry (routinely tested, BD Biosciences)

11. IL-2 PE-Dazzle594, reactivity: human (Biolegend), application: flow cytometry (quality tested, Biolegend)

12. MIP1 $\beta$ PE, reactivity: human ( $Q C$ testing, BD Biosciences), application: flow cytometry (routinely tested, BD Biosciences)

13. TNF $\alpha$ APC, reactivity: human (QC testing, BD Biosciences), application: flow cytometry (routinely tested, BD Biosciences)

14. CD3 PerCP-eFluor710, reactivity: human (ThermoFisher), tested applications: flow cytometry (Thermofisher)

15. CD8 BV711, reactivity: human (Biolegend), application: flow cytometry (quality tested, Biolegend)

16. CD69 BUV395, reactivity: human (QC testing, BD Biosciences), application: flow cytometry (routinely tested, BD Biosciences)

17. CD137 (4-1BB) PE-Cy7, reactivity: human (Biolegend), application: flow cytometry (quality tested, Biolegend)

18. PD-L1 BV421, reactivity: human (Biolegend), application: flow cytometry (quality tested, Biolegend)

19. HLA-DR APC-eFluor780, reactivity: human (ThermoFisher), tested applications: flow cytometry (Thermofisher)

20. CD38 PE, reactivity: human (QC testing, BD Biosciences), application: flow cytometry (routinely tested, BD Biosciences)

21. PD-1 Alexa Fluor 647, reactivity: human (Biolegend), application: flow cytometry (quality tested, Biolegend)

22. CD4 PE-Cy7, reactivity: human (QC testing, BD Biosciences), application: flow cytometry (routinely tested, BD Biosciences)

23. CD14 BUV737, reactivity: human (QC testing, BD Biosciences), application: flow cytometry (routinely tested, BD Biosciences)

24. CD19 BUV737, reactivity: human (QC testing, BD Biosciences), application: flow cytometry (routinely tested, BD Biosciences)

25. HIV-1 Gag PE, reactivity: HIV-1 core antigen (Beckman Coulter), listed under flow cytometry reagents (Beckman Coulter)

\section{Human research participants}

Policy information about studies involving human research participants

Population characteristics

Eligible participants for the bNAb clinical trial were adults aged 18-65 years, HIV-1-infected, on ART for a minimum of 24 months, with plasma HIV-1 RNA levels of 50 copies/ml for at least 18 months (one viral blip of $>50$ but $<500$ copies/ml during this 18 month period was allowed), plasma HIV-1 RNA levels of $<20$ copies/ml at the screening visit, and a current CD4+ T cell count $>500$ cells $/ \mu$ l. Clinical data are summarized in extended data figure 1 and 5 .

To study HIV-specific T cell responses during ART suppression, individuals were recruited at Rockefeller University, that were on ART for at least 4 years. Clinical data for these individuals are shown in extended data figure 2.

Recruitment

Participants of the bNAb+ATI trial were pre-screened for sensitivity of latent proviruses against 3BNC117 and 10-1074 antibodies by bulk PBMC viral outgrowth. Sensitivity was defined as an IC50 $<2 \mu \mathrm{g} / \mathrm{ml}$ for both antibodies against outgrowth virus. Participants harboring sensitive viruses were invited for screening and were enrolled in the study sequentially. Participants were enrolled at the two clinical sites at the Rockefeller University (New York, USA) and Cologne University Hospital (Germany).

HIV-infected individuals on continuous ART were recruited at the Rockefeller University (New York, USA). 


\section{Clinical data}

Policy information about clinical studies

All manuscripts should comply with the ICMJE guidelines for publication of clinical research and a completed CONSORT checklist must be included with all submissions.

Clinical trial registration

Study protocol

Data collection

Outcomes

\section{NCT02825797}

https://clinicaltrials.gov/ct2/show/NCT02825797

Results concerning this clinical trial have been previously published in Mendoza et al., Nature, 561, 479-484 (2018). For this study, we used PBMC samples collected at Rockefeller University or University of Cologne from enrolled HIV-infected trial participants at week -2, 6/7, 12 and 18 (see Extended Data Figures 1 and 5) for analysis.

All primary and secondary outcomes of the trial are described under https://clinicaltrials.gov/ct2/show/NCT02825797. For the immunological exploratory substudy presented here, we pre-selected participants with a specific outcome (maintained viral suppression for $>12$ weeks after analytical treatment interruption).

\section{Flow Cytometry}

\section{Plots}

Confirm that:

Х The axis labels state the marker and fluorochrome used (e.g. CD4-FITC).

Х The axis scales are clearly visible. Include numbers along axes only for bottom left plot of group (a 'group' is an analysis of identical markers).

$\bigotimes$ All plots are contour plots with outliers or pseudocolor plots.

$\bigotimes$ A numerical value for number of cells or percentage (with statistics) is provided.

\section{Methodology}

Sample preparation

Instrument

Software

Cell population abundance

Gating strategy

Cryopreserved PBMCs were thawed, rested, stimulated, fixed, permeabilized and stained according to the demands on each experiment. All details are mentioned in the Methods section.

LSRII (BD Biosciences) and LSR Fortessa (BD) for standard flow cytometry.

Flow cytometry data were collected by DIVA 8.0.1 and analyzed with Flowjo v10 (Treestar).

For Flow Cytometry, we collected 0.1-15M events depending on the experiment. FMO controls and DMSO-treated controls were used as controls.

The generic gating strategy is explained in supplementary figures $1 \& 2$ and extended data figures $6 \& 9$.

Х Tick this box to confirm that a figure exemplifying the gating strategy is provided in the Supplementary Information. 